\title{
Role of ADAM17 in invasion and migration of CD133-expressing liver cancer stem cells after irradiation
}

\author{
SungWoo Hong ${ }^{1}$, Wonhee Hur ${ }^{1}$, Jung Eun Choi ${ }^{1}$, Jung-Hee Kim¹, Daehee Hwang ${ }^{2}$, \\ Seung Kew Yoon ${ }^{1}$ \\ ${ }^{1}$ The Catholic University Liver Research Center and WHO Collaborating Center of Viral Hepatitis, College of Medicine, \\ The Catholic University of Republic of Korea, Seoul, Republic of Korea \\ ${ }^{2}$ Department of New Biology and Center for Plant Aging Research, Institute for Basic Science, DGIST, Daegu, Republic of Korea \\ Correspondence to: Seung Kew Yoon, e-mail: yoonsk@catholic.ac.kr
}

Keywords: cancer stem cells, hepatocellular carcinoma, radioresistance, ADAM17, migration

Received: August 20, 2015

Accepted: February 28, 2016

Published: March 16, 2016

ABSTRACT

We investigated the biological role of CD133-expressing liver cancer stem cells (CSCs) enriched after irradiation of Huh7 cells in cell invasion and migration. We also explored whether a disintegrin and metalloproteinase-17 (ADAM17) influences the metastatic potential of CSC-enriched hepatocellular carcinoma (HCC) cells after irradiation. A CD133-expressing Huh7 cell subpopulation showed greater resistance to sublethal irradiation and specifically enhanced cell invasion and migration capabilities. We also demonstrated that the radiation-induced MMP-2 and MMP-9 enzyme activities as well as the secretion of vascular endothelial growth factor were increased more predominantly in Huh7 ${ }^{\mathrm{CD} 133+}$ cell subpopulations than Huh7 ${ }^{\mathrm{CD} 133-}$ cell subpopulations. Furthermore, we showed that silencing ADAM17 significantly inhibited the migration and invasiveness of enriched $\mathrm{Huh}^{\mathrm{CD} 133+}$ cells after irradiation; moreover, Notch signaling was significantly reduced in irradiated CD133-expressing liver CSCs following stable knockdown of the ADAM17 gene. In conclusion, our findings indicate that CD133-expressing liver CSCs have considerable metastatic capabilities after irradiation of HCC cells, and their metastatic capabilities might be maintained by ADAM17. Therefore, suppression of ADAM17 shows promise for improving the efficiency of current radiotherapies and reducing the metastatic potential of liver CSCs during HCC treatment.

\section{INTRODUCTION}

Hepatocellular carcinoma (HCC) is one of the most devastating malignancies worldwide and is highly prevalent in sub-Saharan Africa and Southeast Asia; moreover, its incidence is currently increasing in Western countries $[1,2]$. Although remarkable advances in the treatment of $\mathrm{HCC}$ have been made, its prognosis is poor due to a high tumor recurrence rate that exceeds $70 \%$ after surgical resection [3] and progressive liver failure caused by underlying liver cirrhosis. Among multiple modalities for the treatment of HCC, radiotherapy has been applied in selected cases. Because liver tissue is highly sensitive to radiation, high-dose conventional radiotherapy against HCC is generally limited due to radiation-induced liver injury. To compensate for this drawback, stereotactic body radiation therapy (SBRT) is recommended for HCC; however, evidence of beneficial survival outcomes for advanced HCC remains insufficient [4]. Recently, the hazards of radiotherapy have been shown in cancer biology and clinically based studies, such as enhancement of cancer cell invasiveness in vitro [5] and an increase in distant metastasis in some cancer patients [6,7]. However, the mechanisms underlying metastasis in HCC after irradiation have not been clarified.

Growing evidence reveals that a subpopulation of tumor cells harboring the ability to propagate, called cancer stem cells (CSCs) or cancer stem-like cells (CSLCs), is responsible for tumor initiation, progression and metastasis. In addition, recent studies have described that CSCs in a variety of human tumors play a key role in tumor recurrence, chemoresistance and radioresistance [8-11]. However, knowledge regarding the role of candidate CSCs in radioresistance of $\mathrm{HCC}$ is limited. Regarding radioresistance associated with CSCs, a previous study reported that glioma stem cells promote radioresistance 
via preferential activation of the DNA damage response [12], and another study demonstrated that radioresistance is associated with reactive oxygen species (ROS) levels in CSCs [13]. We recently demonstrated that CD133expressing liver cancer cells following radiation exposure showed higher activation of the MAPK/PI3K signaling pathway and reduced ROS levels compared with CD133 (-) liver cancer cells [14]. However, the mechanism by which irradiation maintains or reinforces the invasion and migration capabilities of CSCs, which reflects the metastatic potential of tumor cells, remains to be explored. A previous study demonstrated that radiation enhanced HCC cell invasiveness by MMP-9 expression through the PI3K/Akt/NF-kappaB signal transduction pathway [15]. Additionally, another study showed that radiation enhances the long-term metastatic potential of residual HCC through the TMPRSS4-induced epithelialmesenchymal transition in nude mice [16]. However, whether activation of a particular gene related to liver CSCs can lead to metastasis in HCC remains unclear.

A disintegrin and metalloproteinase (ADAM), also known as TNF- $\alpha$ converting enzyme (TACE), plays a key developmental role by processing numerous growth factors and growth factor receptors [17, 18]. Studies have shown that ADAM17 is a potent sheddase of the epidermal growth factor (EGF) family of ligands and regulates EGFR activity in a variety of tumors [19, 20]. Additionally, ADAM17 plays important roles in tumor progression [21], hypoxia-induced tumor cell invasiveness [22] and hypoxia-induced cisplatin resistance [23]. In the present study, we found that ADAM17 was increased in irradiated liver CSCs, suggesting their involvement in the metastatic mechanism of $\mathrm{HCC}$, and furthermore, this metastatic potential of liver CSCs may be decreased by ADAM17. Moreover, aberrant Notch signaling was reportedly related to tumorigenesis, self-renewal of CSCs and metastasis in various human tumors [24], and its downregulation was found to inhibit $\mathrm{HCC}$ cell invasion through inactivation of matrix metalloproteinase 2 (MMP-2), MMP-9 and vascular endothelial growth factor (VEGF) [25]. However, how ADAM17 regulates Notch signaling in liver CSCs after irradiation remains unclear.

In the present study, we explored whether ADAM17 in CD133-expressing liver CSCs plays a key role in radiation-induced tumor cell invasiveness or the metastatic potential of HCC.

\section{RESULTS}

\section{The CD133-expressing Huh7 cell subpopulation exhibited metastatic potential with radioresistance properties}

Recent studies reported that irradiation enriches the population of cells expressing CSC markers [26]. In our previous study, we found that CD133 expression was significantly higher in 15- Gy irradiated Huh $7^{\mathrm{CD} 133+}$ cells than in nonirradiated Huh $7^{\mathrm{CD} 133+}$ cells. In addition, Huh $7^{\mathrm{CD} 133+}$ cells may have greater anti-apoptotic activity due to increased Bcl-2 expression and radioresistance. These CSCs are radioresistant to both intrinsic and extrinsic determinants through various mechanisms, including preferential activation of the DNA damage response, lower cellular ROS levels and activation of survival signaling pathways [12]. Furthermore, in a growing tumor, CSCs regulate metastasis similar to normal stem cell processes [27]. The typical human HCC cell lines include Huh7, Hep3B, HepG2, Sk-hep1, PLC/PRF5 cell, among others. In this study, we isolated liver cancer stem cells (LCSCs) from various $\mathrm{HCC}$ cell lines using a PE-conjugated antiCD133 antibody and a FACs system. In Supplementary Figure S1, we confirmed CD133-expressing LCSCs population in various HCC cell lines by FACs. The percentage of CD133 (+) LCSCs from the Sk-Hep1 cell line was only $0.1 \%$, and therefore we could not use this cell line for further study. By contrast, the percentages of CD133 (+) LCSCs from Hep3B and PLC/PRF5 cell lines were $98.9 \%$ and $86.2 \%$, respectively, and these cells also were inappropriate for further study. However, the ratios of CD133 (+) cells and CD133 (-) cells from the Huh7 cell line were $50.7 \%$ and $49.3 \%$, respectively, which rendered it appropriate for use in further experiments. To determine whether Huh $7^{\mathrm{CD} 133+}$ cells possessed greater metastatic ability than their Huh $7^{\mathrm{CD} 133-}$ cell counterparts in vitro, we performed a migration assay of Huh $7^{\mathrm{CD} 133+}$ and Huh $7^{\mathrm{CD} 133^{-}}$cells sorted from the Huh7 cell line. At 12 , 24 and $48 \mathrm{~h}$ after 15 - Gy irradiation, the migrated cells in each well were stained using a Diff-Quik three-step stain kit (Figure 1A). Then, the numbers of migrated Huh $7^{\mathrm{CD} 133+}$ cells and Huh $7^{\mathrm{CD} 133-}$ cells were counted and compared (Figure 1B). As shown in Figure 1B, the migration ability of Huh $7^{\mathrm{CD} 133+}$ cells was twofold higher than that of Huh $7^{\text {CD133- }}$ cells at 48 h after $15-$ Gy irradiation. Next, to assess the invasion ability of $\mathrm{Huh} 7^{\mathrm{CD} 133+}$ and $\mathrm{Huh} 7^{\mathrm{CD} 133-}$ cells after 15- Gy irradiation, we measured and compared the optical density (OD) values obtained an invasion assay (Figure 1C). At $48 \mathrm{~h}$ after 15- Gy irradiation, the invasion ability of Huh $7^{\mathrm{CD} 133+}$ cells was significantly higher than that of Huh $7^{\mathrm{CD} 133^{-}}$cells. Taken together, these results suggest that irradiation exerts significantly greater stimulatory effects on the migration and invasion of Huh $7^{\mathrm{CD} 133+}$ cells than Huh $7^{\mathrm{CD} 133-}{ }^{-}$cells. Moreover, these results provided additional evidence that compared with $\mathrm{Huh} 7^{\mathrm{CD} 133^{-}}$cells, Huh $7^{\mathrm{CD} 133+}$ cell subpopulations are enriched in CSCs resistant to irradiation.

\section{Secretion of MMP-2 and MMP-9 by the CD133- expressing Huh7 cell subpopulation following irradiation}

MMP enzymes that degrade ECM proteins are a critical component of cell invasion in metastasis [15]. 
In this study, we investigated the gelatinolytic activities of MMP-2 and MMP-9 after 15- Gy irradiation. The radiation-induced MMP-2 and MMP-9 enzyme activities determined by gelatin zymography were significantly increased in Huh $7^{\mathrm{CD} 133+}$ cell supernatants (Figure 2A-2C). As shown in Figure 2B, MMP-2 activity at 12, 24 and $48 \mathrm{~h}$ after $15-$ Gy irradiation was significantly increased in Huh $7^{\mathrm{CD} 133+}$ cell supernatants compared with Huh $7^{\mathrm{CD} 133-}$ cell supernatants. Additionally, MMP-9 activity at 24 and $48 \mathrm{~h}$ after 15 - Gy irradiation was significantly increased in Huh $7^{\mathrm{CD} 133+}$ cell supernatants compared with the control (Figure 2C). These results suggest that upregulation of MMP-2 and MMP-9 secretion after irradiation enhances the invasiveness of liver CSCs.

\section{Secretion of VEGF in CD133-expressing Huh7 cell subpopulations following irradiation}

The expression of VEGF, an important growth factor stimulating angiogenesis, has been associated with tumor
A
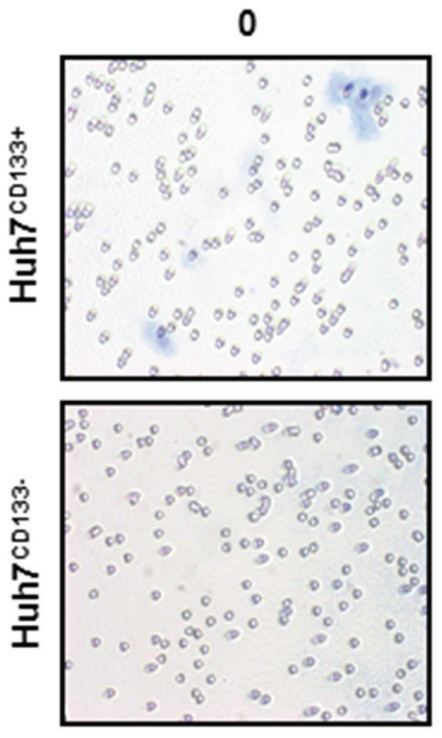

B

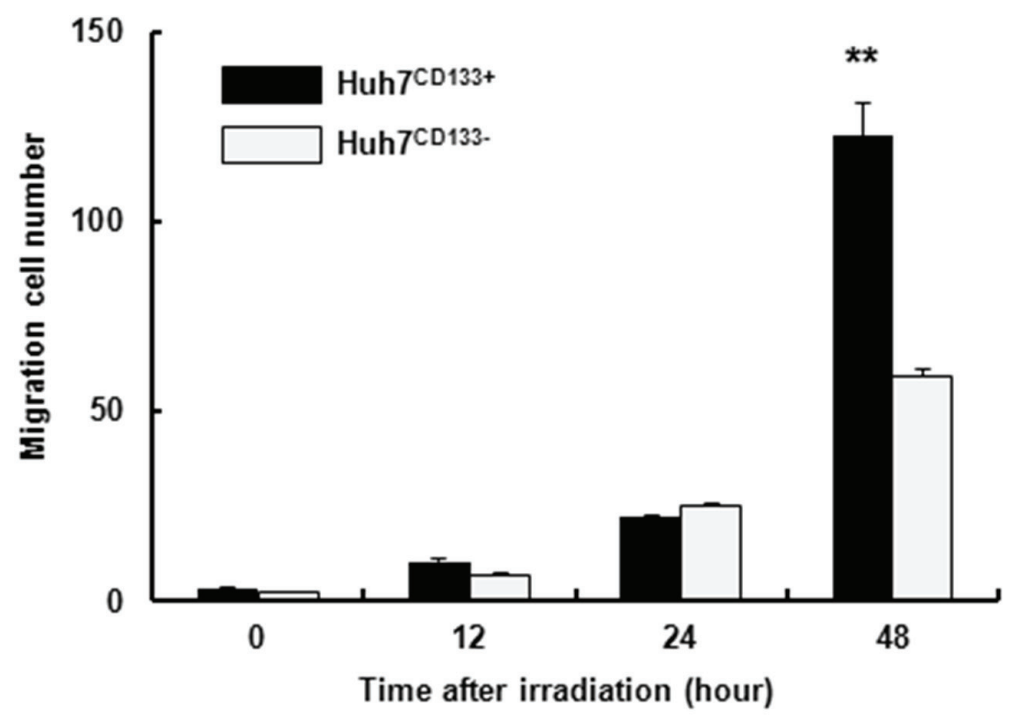

IR (15 Gy)

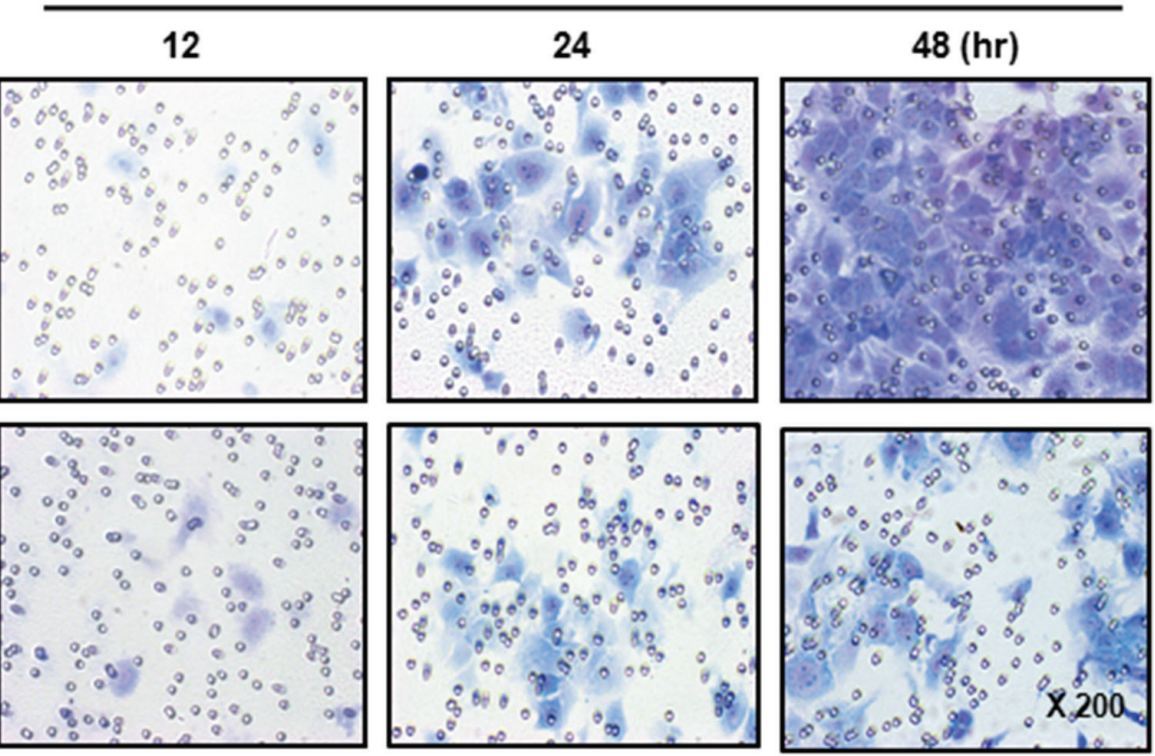

C

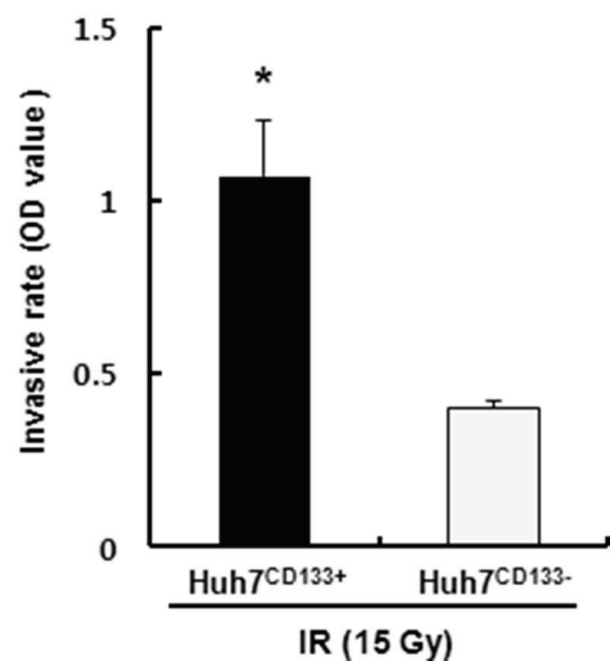

Figure 1: Migration and invasion assay of $\mathrm{Huh} 7^{\mathrm{CD} 133^{+}}$and $\mathrm{Huh} 7^{\mathrm{CD} 133-}$ cells after 15- Gy irradiation. (A) The migratory capacity of Huh $7^{\mathrm{CD} 133^{+}}$and Huh $7^{\mathrm{CD} 133-}$ cells was assessed at 12, 24 and $48 \mathrm{~h}$ using a Transwell migration assay after 15- Gy irradiation. (B) The numbers of migrated Huh $7^{\mathrm{CD} 133+}$ and Huh $7^{\mathrm{CD} 133-}$ cells was compared. The results are expressed as means \pm SD of three independent experiments. ${ }^{* *} P<0.01$, Huh $7^{\mathrm{CD} 133^{+}}(48 \mathrm{~h}) v s$. Huh $7^{\mathrm{CD} 133^{-}}$(48 h). (C) Invasive potential of Huh $7^{\mathrm{CD} 133^{+}}$and Huh7 $7^{\mathrm{CD} 133^{-}}$cells was measured using Matrigel-coated transwells after $48 \mathrm{~h}$ of 15 - Gy irradiation. The results are expressed as means $\pm \mathrm{SD}$ of three independent experiments. $* P<0.05$, Huh7 ${ }^{\mathrm{CD} 133^{+}}$vs. Huh7 ${ }^{\mathrm{CD} 133^{-}}$cells. 
progression, metastasis and invasion in HCC [28] and other tumors [29]. A previous study reported that VEGF levels were enhanced by ionizing radiation in glioblastoma cells [30]. In this regard, we investigated whether the metastatic potential of liver CSCs after 15- Gy irradiation is associated with VEGF expression levels by Western blot and enzyme-linked immunosorbent assay (ELISA). As shown in Figure 2D, the rate of increase in VEGF expressions in irradiated Huh $7^{\mathrm{CD} 133+}$ cells increased over time compared with irradiated Huh $7^{\mathrm{CD} 133-}$ cells determined by Western blot. In addition, the increased VEGF levels in supernatants from irradiated $\mathrm{Huh} 7^{\mathrm{CD} 133+}$ cells tended to increase over time compared with irradiated Huh7CD133cells albeit not significantly so (Figure 2E). These corresponding results from Western blots and ELISA indicate that CD133-expressing LCSCs after radiation have greater angiogenic potential, leading to enhanced metastatic ability.

\section{CD133 expression following irradiation increased metastatic potential in vivo}

To determine the effect of CD133-expressing LCSCs following radiation treatment on metastatic potential in vivo [31], irradiated Huh $7^{\mathrm{CD} 133+}$ or Huh $7^{\mathrm{CD} 133-}$ were injected via the tail vein. At 10 weeks after tumor cell injection via the tail vein, lung metastases were detected in $7(70 \%)$ of the 10 mice injected with $1 \times 10^{6} \mathrm{Huh} 7^{\mathrm{CD} 133+}$ cells after irradiation but not in the 10 mice injected with Huh $7^{\text {CD133- }}$ cells (Table 1, Figure $3 \mathrm{~A}$ ). In the representative $\mathrm{H} \& \mathrm{E}$ staining of the lung tissues in Huh $7^{\mathrm{CD} 133+}$ injection group, tumors exhibited more aggressive invasion into surrounding lung tissue, undifferentiated and markedly pleomorphic tumor cells, suggesting poorly differentiated carcinoma (Figure 3B). In addition, subcutaneous metastases were detected in 2 of 10 mice with $1 \times 10^{6}$ Huh $7^{\mathrm{CD} 133+}$ cells. However, no metastases were observed in the heart, kidney, spleen or liver in this group. These findings suggest that CD133-expressing LCSCs after irradiation have metastatic potential.

\section{Differential profiling of metastasis-associated gene expression between $\mathrm{Huh} 7^{\mathrm{CD} 133+}$ and Huh $7^{\text {CD133- }}$ cells following irradiation}

To evaluate how the cellular processes of Huh $7^{\mathrm{CD} 133+}$ and Huh $7^{\mathrm{CD} 133+}$ cells differ after irradiation, a cDNA microarray was used to analyze the gene expression profiles

A

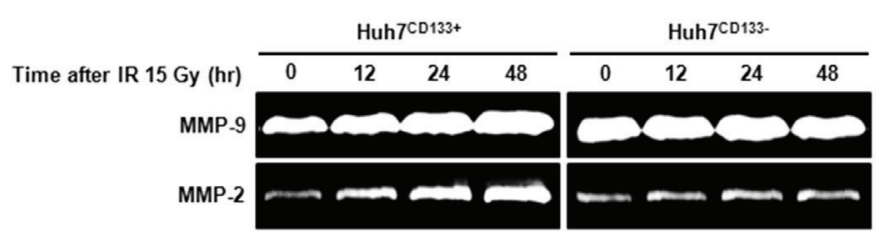

B

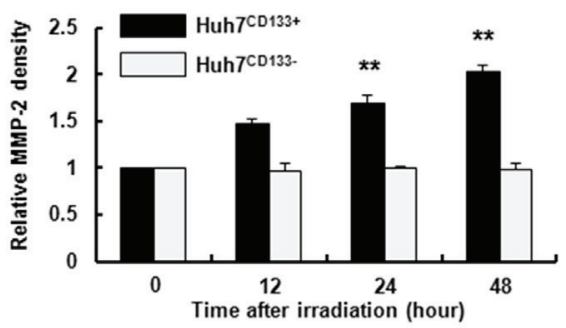

D

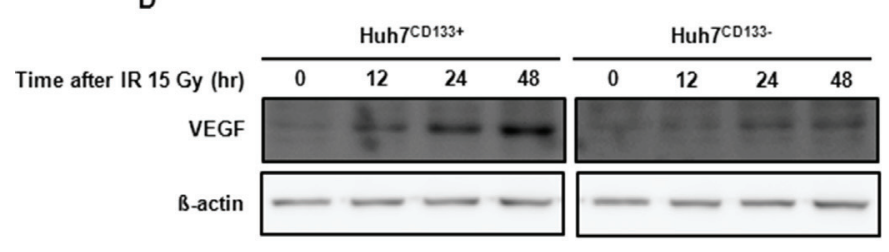

C

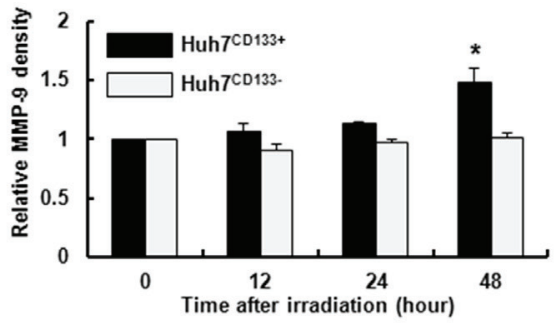

E

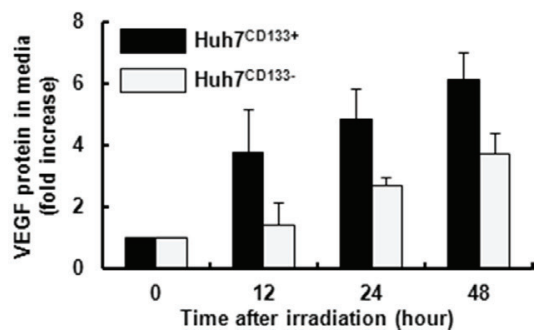

Figure 2: Gelatin zymography using conditioned $\mathrm{Huh} 7^{\mathrm{CD} 133+}$ and $\mathrm{Huh} 7^{\mathrm{CD} 133-}$ cell culture media after $15-\mathrm{Gy}$ irradiation. (A) MMP activities are visualized as white (clear) bands, corresponding to MMP-2 and MMP-9. (B and C) MMP-2 and MMP-9 band densities were quantified. The results are expressed as means $\pm \mathrm{SD}$ of three independent experiments. $* * P<0.01 v s$. Huh $7^{\mathrm{CD} 133+}$ and Huh7 $7^{\mathrm{CD} 133-}$ controls. ${ }^{*} P<0.05 v s$. Huh $7^{\mathrm{CD} 133^{+}}$and Huh7 $7^{\mathrm{CD} 133^{-}}$controls. (D) VEGF expression levels in Huh7 $7^{\mathrm{CD} 133^{+}}$and Huh7 ${ }^{\mathrm{CD} 133^{-}}$cells after 15- Gy irradiation were compared by Western blotting. (E) VEGF protein levels in conditioned media from Huh $7^{\mathrm{CD} 133^{+}}$and Huh $7^{\mathrm{CD} 133^{-}}$cells after 15- Gy irradiation were compared by ELISA. 
Table 1: Establishment of an in vivo metastasis model of human HCC cell line in nude mice

\begin{tabular}{|c|c|c|c|c|c|c|c|c|c|c|}
\hline \multirow{2}{*}{ Cell line } & \multirow{2}{*}{$\begin{array}{l}\text { Injection } \\
\text { site }\end{array}$} & \multirow{2}{*}{$\begin{array}{c}\text { Cell } \\
\text { number }\end{array}$} & \multirow{2}{*}{$\begin{array}{l}\text { Number of } \\
\text { nude mice } \\
\text { injected }(n)\end{array}$} & \multirow{2}{*}{ Weeks } & \multicolumn{5}{|c|}{ Hematogenic metastases } & \multirow{2}{*}{$\begin{array}{c}\text { Subcutaneous } \\
\text { tumor } \\
\text { formation }\end{array}$} \\
\hline & & & & & Lung & Liver & Spleen & Kidney & Heart & \\
\hline Huh7 $7^{\text {CD133+ }}$ & i.v. & $10^{6}$ & 10 & 10 & $7 / 10$ & $0 / 10$ & $0 / 10$ & $0 / 10$ & $0 / 10$ & $2 / 10$ \\
\hline Huh7 ${ }^{\text {CD133- }}$ & i.v. & $10^{6}$ & 10 & 10 & $0 / 10$ & $0 / 10$ & $0 / 10$ & $0 / 10$ & $0 / 10$ & $0 / 10$ \\
\hline
\end{tabular}

*i.v.: Intravenous injection.

A

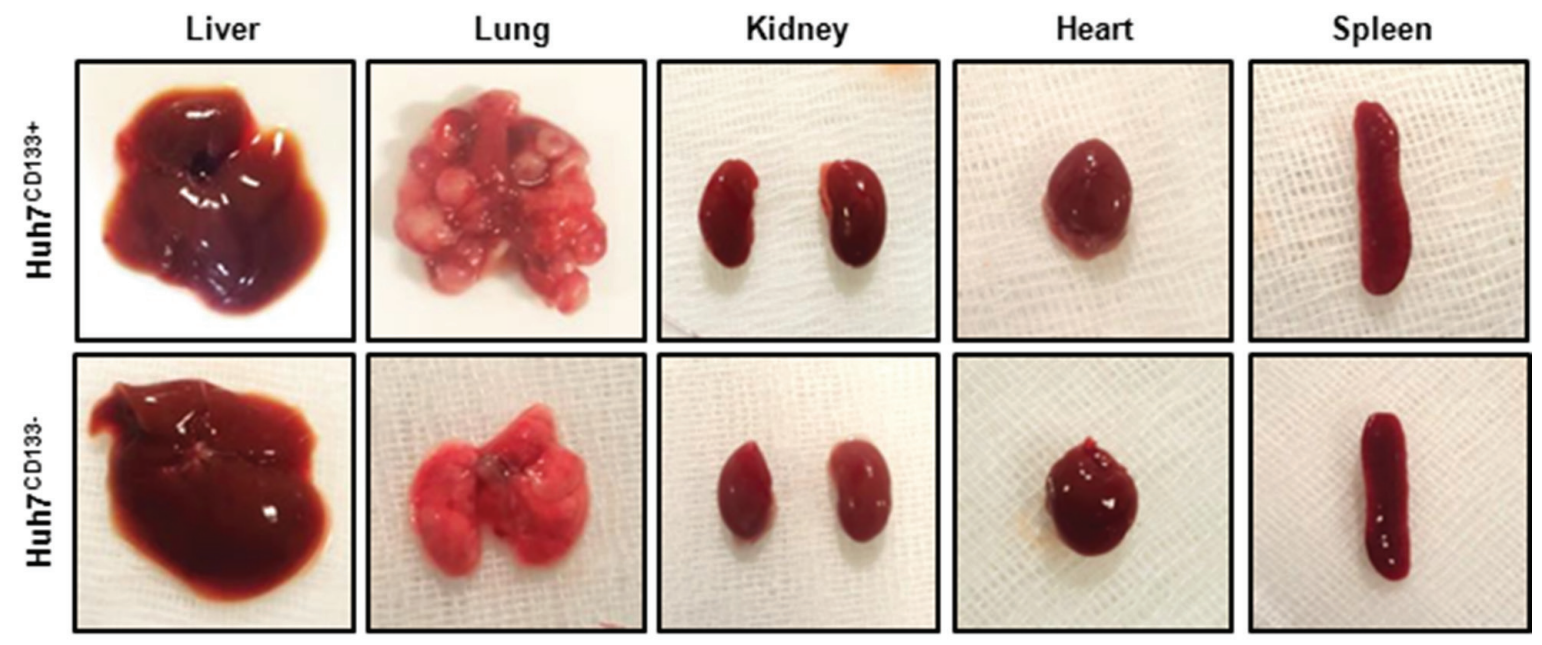

B
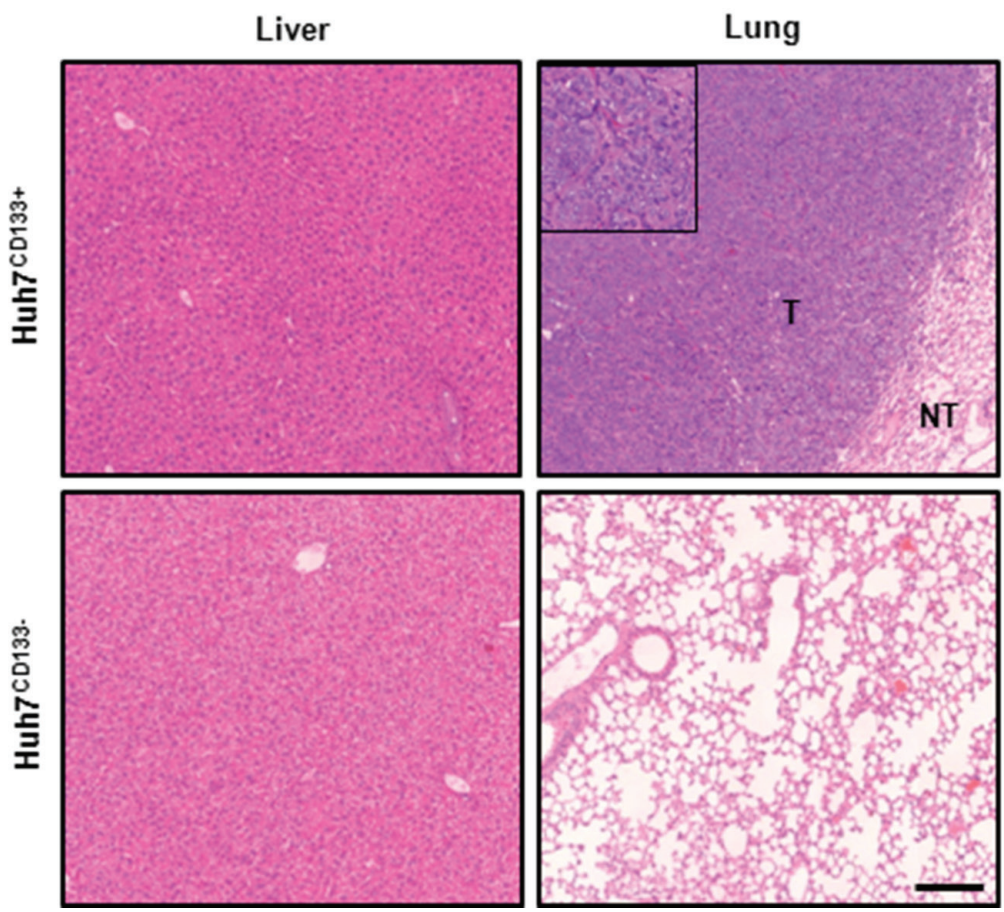

Figure 3: Gross photography of dissected organs and $H \& E$ staining from representative tumor from metastasis in vivo model. (A) Representative images of dissected organs within the body after tail vein injection of irradiated Huh $7^{\mathrm{CD} 133+}$ and Huh $7^{\mathrm{CD} 133^{-}}$cells. Multiple nodules were observed in both lung but none in Huh $7^{\mathrm{CD} 133^{-}}$injection group. In addition, no metastatic lesions were found in other organs except lung. (B) Representative $\mathrm{H} \& \mathrm{E}$ staining of the lung tissues in Huh $7^{\mathrm{CD} 133+}$ injection group showed tumorous portion (T) and non-tumorous portion (NT). Tumors exhibited more aggressive invasion into surrounding lung tissue, undifferentiated and markedly pleomorphic tumor cells, suggesting poorly differentiated carcinoma. Scale bar, $200 \mu \mathrm{m}$. 
of Huh $7^{\mathrm{CD} 133^{+}}$and Huh7 $7^{\mathrm{CD} 133^{-}}$cells at 12 and $24 \mathrm{~h}$ after 15- Gy irradiation. The mRNA expression profiles of Huh $7^{\mathrm{CD} 133^{+}}$and $\mathrm{Huh} 7^{\mathrm{CD} 133^{-}}$cells were comparatively analyzed using a cDNA microarray containing 592 genes. Fifteen percent of the genes ( 89 genes) that displayed a greater than 1.5-fold change in $\mathrm{Huh} 7^{\mathrm{CD} 133+}$ expression compared with the control Huh $7^{\mathrm{CD} 133-}$ cells were associated with metastasis (Figure 4A). Grouping of the 89 metastasisassociated genes according to their biological function was performed between $\mathrm{Huh} 7^{\mathrm{CD} 133+}$ and Huh $7^{\mathrm{CD} 133-}$ cells at 12 and $24 \mathrm{~h}$ after irradiation. Among the genes increased in Huh $7^{\mathrm{CD} 133+}$ cells $12 \mathrm{~h}$ post-irradiation, $13.5 \%$ (12 genes) were related to migration, $29.2 \%$ (26 genes) to cell adhesion, $25.8 \%$ (23 genes) to cell mobility and $7.8 \%$ to angiogenesis. Additionally, of the genes that were increased $24 \mathrm{~h}$ post-irradiation, $12.3 \%$ (11 genes) were associated with migration, $38.2 \%$ (34 genes) with cell adhesion, 32.6\% (29 genes) with cell mobility, 9\% (9 genes) with angiogenesis and $6.7 \%$ (6 genes) with VEGF signaling. Among the genes, for validation we selected 14 candidate reference genes (ADAM17, ADCY3, ALDH2, ALDH3, ALDH7, BOLA2, LEPR, MTSS1, NME1, KRT18, Notch1, PHLDA1, PDGFR and FANCD2) that showed overlapping upregulation at 12 and $24 \mathrm{~h}$ post-irradiation in Huh $7^{\text {CD133+ }}$ cells. Reverse transcription polymerase chain reaction (RT-PCR) for validation of selected candidate genes was performed in sorted Huh $7^{\mathrm{CD} 133^{+}}$and Huh $7^{\mathrm{CD} 133^{-}}$ cells (Supplementary Table S1). However, only two genes showed at least a 1.5-fold difference: ADAM17 was increased 1.9-fold and metastasis suppressor 1 (MTSS1) was decreased 0.5 -fold in Huh7 ${ }^{\text {CD133+ }}$ cells compared with Huh7 ${ }^{\mathrm{CD} 133-}$ cells (Figure 4B). ADAM17 is a transmembrane and secreted protein with important roles in various metastatic functions, such as adhesion, migration, invasion and secretion of MMP-2 and MMP-9 [32]. In contrast, MTSS1 reportedly exerts its metastasis suppressor functions by acting as a scaffold protein that interacts with actin-associated proteins to regulate lamellipodia formation [33]. Therefore, we assessed the effect of ADAM17 on metastasis potential in CD133-expressing LCSCs after irradiation.

\section{Expression of ADAM17 in CD133-expressing liver CSCs following irradiation}

To confirm the difference in ADAM17 protein levels in Huh $7^{\mathrm{CD} 133^{+}}$and Huh $7^{\mathrm{CD} 133^{-}}$cells after irradiation, cells were cultured and harvested at 12, 24 and $48 \mathrm{~h}$ after 15- Gy irradiation. Western blot was performed using antibodies against ADAM17. The ADAM17 protein level was increased significantly in Huh $7^{\mathrm{CD} 133+}$ cells compared with the control at 12, 24 and $48 \mathrm{~h}$ after treatment with 15- Gy irradiation. However, the ADAM17 protein level was significantly decreased in Huh $7^{\mathrm{CD} 133-}$ cells compared with the control (Figure 4C and 4D). Additionally, the MTSS1 protein level was not changed in $\mathrm{Huh} 7^{\mathrm{CD} 133^{+}}$or Huh $7^{\text {CD133- }}$ cells at 12,24 and $48 \mathrm{~h}$ after irradiation, in agreement with the mRNA level based on RT-PCR, but no significant difference between the two cell groups was observed (Supplementary Figure S2A and S2B). These results suggest that overexpression of ADAM17 is associated with cell invasiveness, angiogenesis and migration, and could contribute to metastasis after radiotherapy for the treatment of HCC.

\section{ADAM17 mediates cell migration, invasion and wound healing in CD133-expressing liver CSCs following radiation exposure}

ADAM17 promotes tumor-induced angiogenesis through upregulation of growth factors such as VEGF via MAP kinase activation [34]. In the present study, ADAM17 in Huh $7^{\mathrm{CD} 133+}$ cells (high metastatic potential) was knocked down using small interfering RNA (siRNA) to suppress metastasis. To assess whether the migration activity of CD133-expressing liver CSCs is influenced by ADAM17 silencing, Huh $7^{\mathrm{CD} 133^{+}}$and Huh $7^{\mathrm{CD} 133^{-}}$cells were transfected with $10 \mathrm{nM}$ siADAM17 or $10 \mathrm{nM}$ scrambled siRNA. ADAM17 expression after ADAM17 siRNA $(10 \mathrm{nM})$ transfection was markedly suppressed (greater than $80 \%$ ) in both cell types within 2 days, whereas no change in ADAM17 expression was observed in either cell type following treatment with scrambled siRNA (10 nM) (Figure 5A). Next, we investigated whether silencing of ADAM17 expression decreased the migration ability of liver CSCs after irradiation. In both cell types treated with mock siRNA, the migration ability of $\mathrm{Huh} 7^{\mathrm{CD} 133+}$ cells was higher than that of Huh $7^{\mathrm{CD} 133^{-}}$cells (Figure 5B), indicating the metastatic potential of CD133-expressing liver CSCs. Notably, we found that the migration ability of Huh $7^{\mathrm{CD} 133+}$ cells was significantly reduced after silencing ADAM17 compared with mock control and scrambled siRNA, while that of Huh $7^{\mathrm{CD} 133-}$ cells was unchanged (Figure 5B). These results suggest that ADAM17 expression in CD133-expressing liver CSCs plays a pivotal role in the metastasis of HCC after irradiation. To suppress ADAM17 expression effectively, stable cell lines expressing shRNA against human ADAM17 were generated by lentiviral transductions in Huh7 cells. As shown in Figure 5C and 5D, ADAM17 mRNA and protein levels were suppressed effectively in ADAM17 transfected Huh7 cells compared with cells expressing negative control shRNA (shNC). Furthermore, shADAM17 $7^{\mathrm{CD} 133^{+}}$and shADAM17 $7^{\mathrm{CD} 133^{-}}$ cells following sorting using an anti-CD133 FACs antibody were suppressed compared with their shNC controls (Supplementary Figure S3A). In addition, CD133 protein levels were decreased in shADAM17 ${ }^{\text {CD133- }}$ and shNC ${ }^{\mathrm{CD} 133^{-}}$cells after sorting (Supplementary Figure S3B). After successful establishment of the stable ADAM17 knockdown cell line, we investigated whether knockdown of ADAM17 suppresses the metastatic potential of CD133-expressing liver CSCs, such as their wound healing, migration and invasion, after 15- Gy 
irradiation. Four cell groups $\left(\mathrm{Huh} 7^{\mathrm{CD} 133+}\right.$, Huh $7^{\mathrm{CD} 133^{-}}$, shNC ${ }^{\mathrm{CD} 133^{+}}$and $\operatorname{shADAM} 17^{\mathrm{CD} 133^{+}}$) were examined in terms of their wound healing abilities analyzed after 15- Gy irradiation. The wound healing ability of shADAM1 $7^{\text {CD133+ }}$ cells was significantly inhibited at $48 \mathrm{~h}$ compared with shNC ${ }^{\mathrm{CD} 133+}$ cells and Huh7 $7^{\mathrm{CD} 133+}$ cells. However, no changes in the wound healing ability of $\mathrm{Huh} 7^{\mathrm{CD} 133^{-}}$cells were observed compared with the control (Figure 6A and 6B). Next, we performed migration assays. As shown in Figure $6 \mathrm{C}$ and $6 \mathrm{D}$, silencing of ADAM17 by shRNA in Huh $7^{\mathrm{CD} 133+}$ cells significantly inhibited migration ability at $48 \mathrm{~h}$ compared with that of shNCCD133+ cells and Huh $7^{\mathrm{CD} 133+}$ cells. In addition, we performed invasion assays to determine the invasiveness of liver CSCs after irradiation. The invasion rate of shADAM $17^{\mathrm{CD} 133+}$ was significantly lower than that of shNC $\mathrm{CD}^{133+}$ cells (Figure 6E). Moreover, we assayed VEGF levels in shADAM17 ${ }^{\mathrm{CD} 133+}$ and shNC ${ }^{\mathrm{CD} 133+}$ cell culture media over time after irradiation. The VEGF levels in shADAM $17^{\mathrm{CD} 133+}$ cell culture medium were significantly decreased at 24 and $48 \mathrm{~h}$ after irradiation compared with shNC ${ }^{\mathrm{CD} 133+}$ cell culture medium (Supplementary Figure S4). Taken together, these results demonstrated that silencing of ADAM17 significantly inhibited the migration and invasiveness of liver CSCs after irradiation, suggesting that suppression of ADAM17 after radiotherapy could prevent metastasis in $\mathrm{HCC}$.

\section{Suppression of ADAM17 inhibits the migration ability of liver CSCs in vivo}

Although in vitro studies elucidated the role of ADAM17 in the metastatic mechanism of CD133expressing liver CSCs after irradiation, further in vivo evidence is necessary to confirm the role of ADAM17. First, we confirmed that the migration ability of irradiated

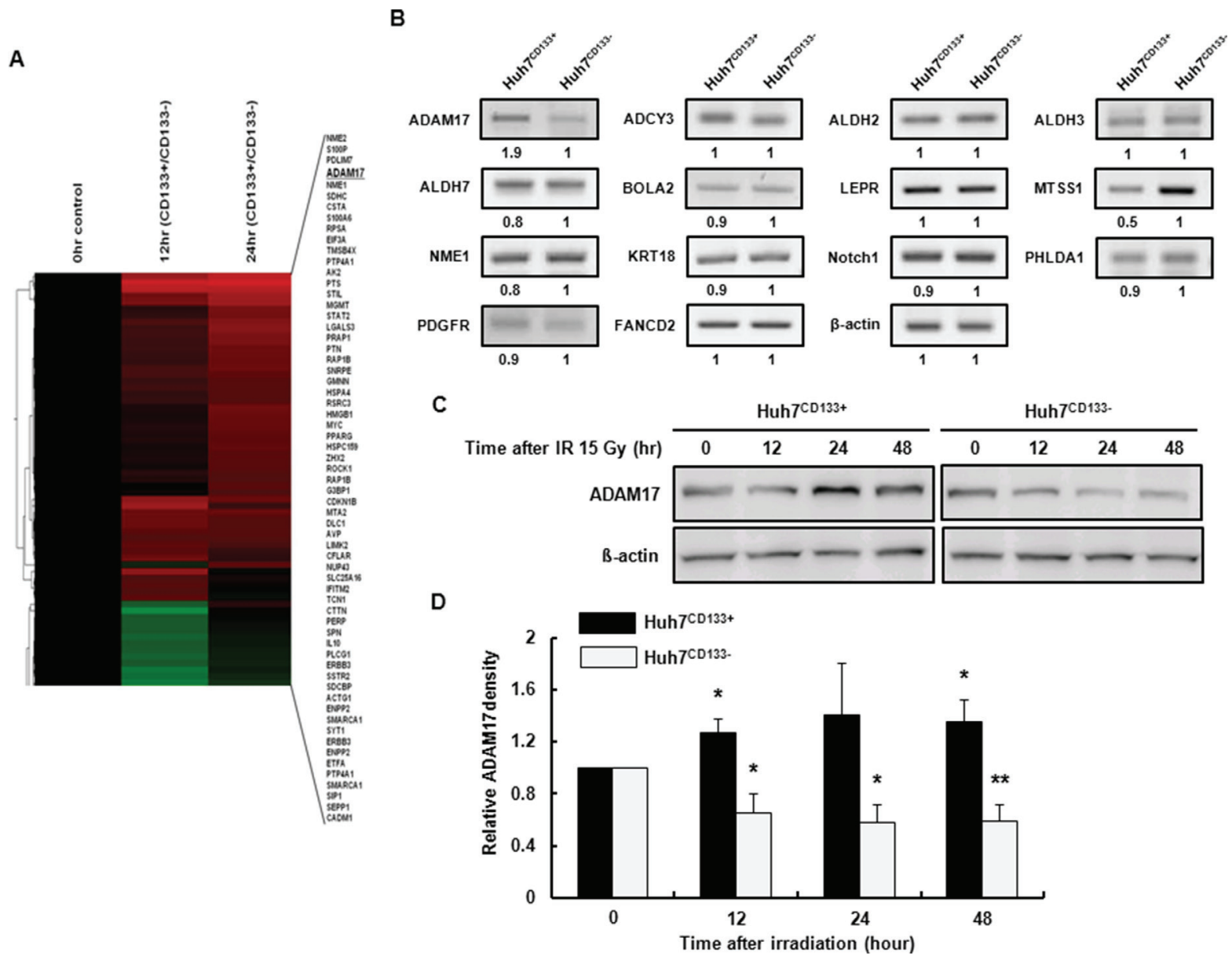

Figure 4: cDNA microarray analysis of the expression profiles of metastasis-associated genes in $\mathrm{Huh}^{\mathrm{CD} 133+}$ and Huh $7^{\mathrm{CD}^{133-}}$ cells at 12 and $24 \mathrm{~h}$ after 15- Gy irradiation. (A) DEGs between Huh $7^{\mathrm{CD} 133^{+}}$and Huh $7^{\mathrm{CD} 133^{-}}$cells. The columns show DEGs in Huh $7^{\mathrm{CD} 133^{+}}$and Huh7 ${ }^{\mathrm{CD} 133^{-}}$cells at 12 and $24 \mathrm{~h}$. Colors represent increases (red) and decreases (green) in CD133+ expression under each condition. (B) The expression levels of metastasis-associated genes were validated in Huh7 $7^{\mathrm{CD} 133^{+}}$and Huh7 ${ }^{\mathrm{CD} 133-}$ cells at 12 and $24 \mathrm{~h}$ after 15- Gy irradiation using RT-PCR. (C) Western blot analysis of ADAM17 protein levels after 15- Gy irradiation of Huh7 ${ }^{\mathrm{CD} 133+}$ and Huh $7^{\mathrm{CD} 133-}$ cells. $\beta$-actin was used as a loading control. (D) Band densities were quantified using the TINA imaging analysis software and normalized to $\beta$-actin expression. The data shown are the means $\pm \mathrm{SE}$ of three independent experiments. ${ }^{* *} P<0.01 v s$. Huh7 ${ }^{\mathrm{CD} 133+}$ and Huh $7^{\mathrm{CD} 133+}$ controls. ${ }^{*} P<0.05$ vs. Huh $7^{\mathrm{CD} 133^{-}}$and Huh $7^{\mathrm{CD} 133^{-}}$controls. 
Huh $7^{\mathrm{CD} 133^{+}}$and Huh7 $7^{\mathrm{CD} 133^{-}}$cells after intrasplenic vein delivery could be visualized by in vivo NIR fluorescence imaging (Supplementary Figure S5A). Cells were labeled with NIR $79724 \mathrm{~h}$ before intrasplenic vein injection. Cells $\left(2 \times 10^{5}\right)$ from each group were injected and the NIR signal intensity monitored. Ten days after injection, Huh $7^{\mathrm{CD} 133+}$ and Huh $7^{\mathrm{CD} 133}$ cells migrated out of the spleen toward other organs (liver and lung), and the cell migration area percentages were analyzed using the maestro imaging system (Supplementary Figure S5B). The migration area percentage of $\mathrm{Huh} 7^{\mathrm{CD} 133+}$ cells increased to a greater degree than that of Huh $7^{\mathrm{CD} 133-}$ cells after irradiation. Furthermore, the NIR fluorescent signal intensity of shNC ${ }^{\mathrm{CD} 133+}$ cells in the abdomen increased over time and spread throughout the body of nude mice, whereas the fluorescent signal intensity of shADAM17 ${ }^{\mathrm{CD} 133+}$ cells slowly increased in the abdomen and their spread throughout the body was delayed (Figure 7A and 7B). These results demonstrated that the overall NIR fluorescent signal intensity was significantly reduced in the mice injected with ADAM17-suppressed Huh $7^{\mathrm{CD} 133+}$ cells compared with ADAM17-nonsuppressed Huh $7^{\mathrm{CD} 133+}$ cells. After imaging analysis, the mice were sacrificed on day 10 and the liver, kidney, spleen, lung and heart were harvested for imaging of the individual organs. NIR-stained shNCCD133+ cells migrated to the liver, kidney, spleen, lung and heart 10 days after intrasplenic vein injection, while NIR-stained shADAM1 ${ }^{\mathrm{CD} 133+}$ cells slowly migrated to other organs after injection (Figure 7C and 7D). Furthermore, to identify the human-derived migrated cells in the liver of the nude mice after

A

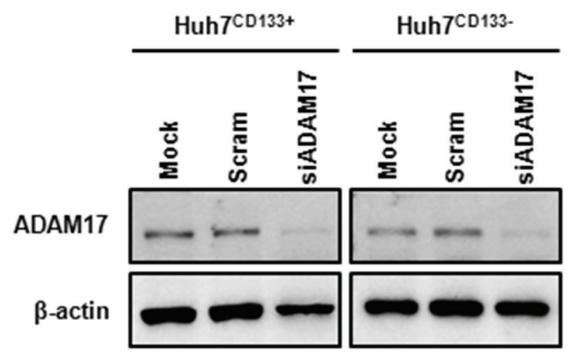

mRNA
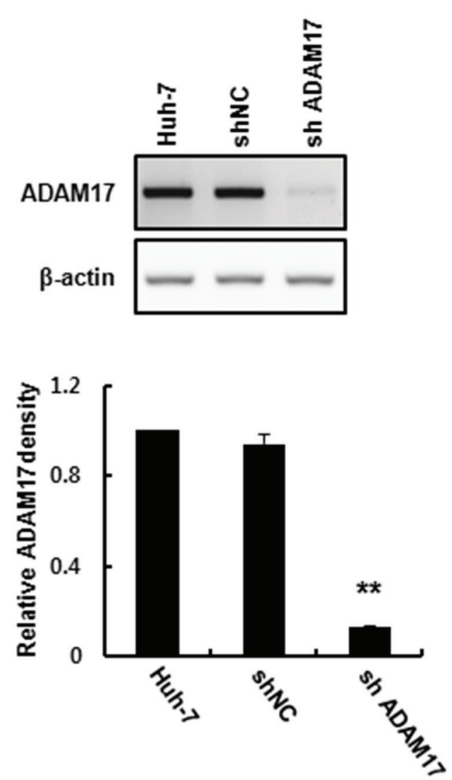

D
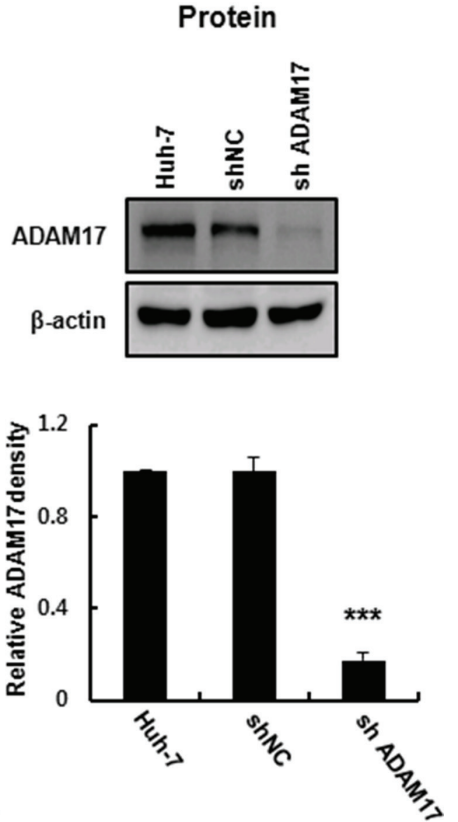

Figure 5: Establishment of an ADAM17-knockdown cell line using a lentiviral expression system. (A) ADAM17 mRNA expression in Huh $7^{\mathrm{CD} 133+}$ and Huh7 ${ }^{\mathrm{CD} 133-}$ cells at $24 \mathrm{~h}$ determined by RT-PCR following transfection of ADAM17 siRNA. (B) Transwell migration assays of Huh $7^{\mathrm{CD} 133+}$, Huh $7^{\mathrm{CD} 133-}$, scram siRNA Huh $7^{\mathrm{CD} 133+}$ and ADAM17 siRNA Huh7 ${ }^{\mathrm{CD} 133^{+}}$cells after 15- Gy irradiation. Images were captured at $48 \mathrm{~h}$ under $\times 40$ magnification. The numbers of migrated Huh7 $7^{\mathrm{CD} 133^{+}}$, Huh $7^{\mathrm{CD} 133^{-}}$, scram siRNA Huh7 $7^{\mathrm{CD} 133^{+}}$and ADAM17 siRNA Huh $7^{\mathrm{CD} 133+}$ cells were compared. ${ }^{*} P<<0.01$, Huh7 $7^{\mathrm{CD} 133+}(48 \mathrm{~h}) v s$. Huh $7^{\mathrm{CD} 133-}$ cells $(48 \mathrm{~h}) .{ }^{* * *} P<0.001, \mathrm{Huh} 7^{\mathrm{CD} 133+}(48 \mathrm{~h}) v s$. siADAM17 Huh $7^{\mathrm{CD} 133+}$ cells $(48 \mathrm{~h})(\mathbf{C})$ ADAM17 mRNA levels in shNC and shADAM17 cells were analyzed using RT-PCR after infection with lentivirus. Band densities were quantified using the TINA imaging analysis software and normalized to $\beta$-actin expression. The data shown are the means $\pm \mathrm{SE}$ of three independent experiments. ${ }^{*} P<0.01 v s$. shNC cells and shADAM17 cells. (D) ADAM17 protein levels in shNC and shADAM17 cells were analyzed by Western blot analysis after infection with lentivirus. Band densities were quantified using the TINA imaging analysis software and normalized to $\beta$-actin expression. The data shown are the means $\pm \mathrm{SE}$ of three independent experiments. $* * * P<0.001$ vs. shNC cells and shADAM17 cells. 
intrasplenic vein injection, immunohistochemical staining for human albumin was performed. The expression levels of human albumin were markedly higher in the livers of nude mice injected with shNC ${ }^{\mathrm{CD} 133+}$ cells compared with those injected with shADAM17 ${ }^{\mathrm{CD} 133^{+}}$(Figure $7 \mathrm{E}$ ). These results provide evidence that ADAM17 inhibits the migration and metastatic potential of CD133-expressing liver CSCs after radiotherapy and may serve as a prognostic marker of recurrence and metastasis of HCC following radiotherapy.

\section{The Notch signaling pathway is inhibited by suppression of ADAM17 in CD133-expressing liver CSCs}

The Notch, Hedgehog and Wnt signaling pathways are involved in metastasis of liver CSCs to distant organs

A

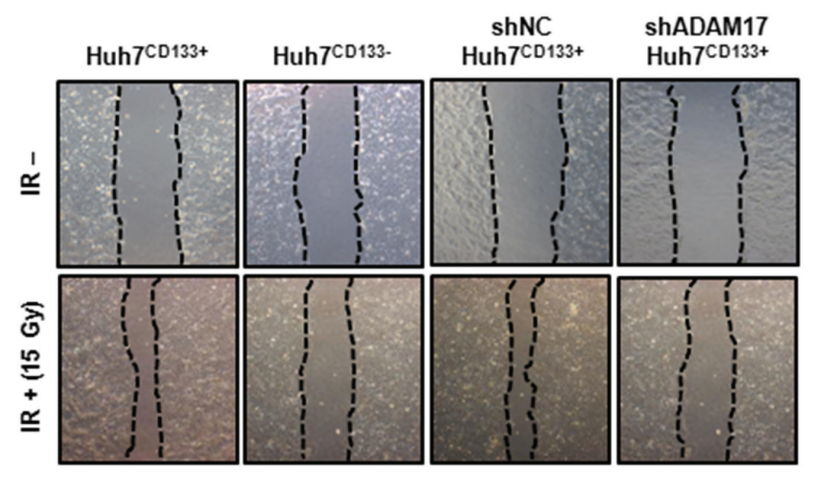

C D
[35]. ADAM17 is an activator of the Notch pathway and is overexpressed in a variety of diseases, including cancers [36]. Among these pathways, Notch signaling reportedly affects angiogenesis [37] and metastasis [38]. The Notch intracellular domain (NICD) is cleaved from the plasma membrane and translocates into the nucleus forming a transcriptional activation complex after binding to $\mathrm{CSL} / \mathrm{RBPJk} / \mathrm{Su}(\mathrm{H})$ and Mastermind (MAML). This heteromeric complex activates the transcription of target genes such as HES [39]. In the present study, to determine the association of Notch signaling with liver CSCs with high metastatic potential after irradiation, we assessed the expression of NICD in the ADAM17-suppressed CD133expressing liver CSCs after irradiation using Western blotting. NICD expression was reduced significantly in shADAM1 $7^{\mathrm{CD} 133+}$ cells at 24 and $48 \mathrm{~h}$ after irradiation compared with that in shNC ${ }^{\mathrm{CD} 133+}$ cells (Figure 8A and 8B).

B

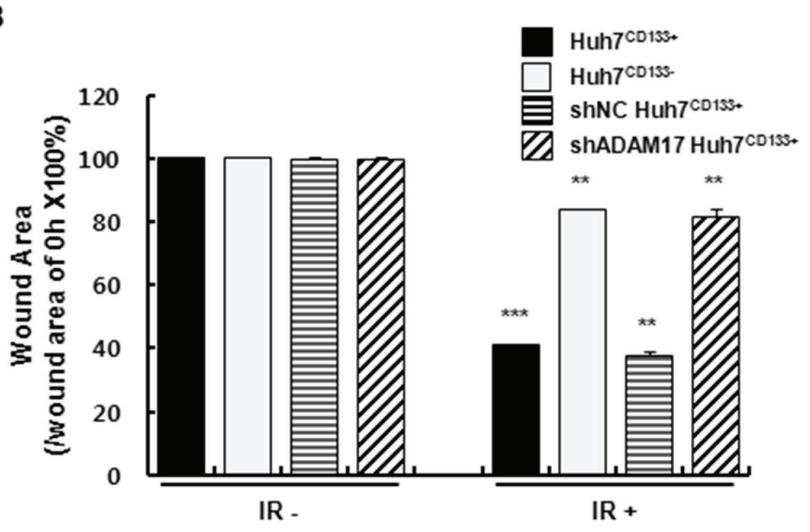

E
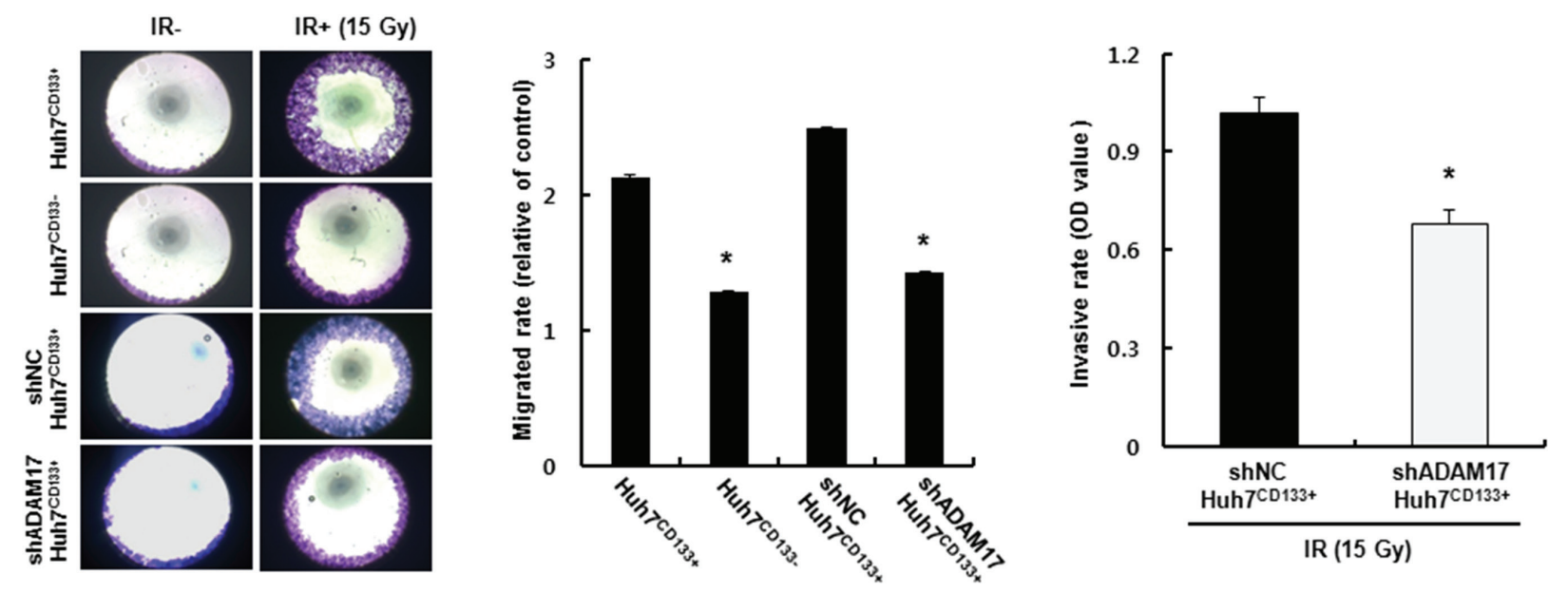

Figure 6: Changes in shADAM1 ${ }^{\mathrm{CD133}+}$ and $\mathrm{shNC}^{\mathrm{CD133+}}$ cell migration after 15- Gy irradiation. (A) Wound healing assay in Huh7 $7^{\mathrm{CD} 133+}$, Huh7 $7^{\mathrm{CD} 133-}$, shNC ${ }^{\mathrm{CD} 133+}$ and shADAM17 $7^{\mathrm{CD} 133+}$ after $15-$ Gy irradiation. Four group of cells were plated on 24-well plates $\left(1 \times 10^{5}\right.$ cells /well $)$ and wounded with a disposable pipette tip. Wound closure was monitored for $48 \mathrm{~h}$ after irradiation. (B) Cell wound area percentages were analyzed using Optimas 6.5 software and compared with those at time zero. $* * * P<0.001, \mathrm{Huh} 7^{\mathrm{CD} 133+}(48 \mathrm{~h}) v s . \mathrm{Huh} 7^{\mathrm{CD} 133+}$ cells $(0 \mathrm{~h}) .{ }^{* *} P<0.01, \operatorname{Huh} 7^{\mathrm{CD} 133-}(48 \mathrm{~h}) v s . \mathrm{Huh}^{\mathrm{CD} 133-}$ cells $(0 \mathrm{~h}) . * * P<0.01, \operatorname{shNC}^{\mathrm{CD} 133^{+}}(48 \mathrm{~h}) v s . \operatorname{shNC}^{\mathrm{CD} 133+}$ cells $(0 \mathrm{~h}) .{ }^{* *} P<0.01$, shADAM17 $7^{\mathrm{CD} 133^{+}}(48 \mathrm{~h}) v \mathrm{~s}$. shADAM17 $7^{\mathrm{CD} 133+}$ cells $(0 \mathrm{~h})$. (C) Migrated cells stained crystal violet (purple color). (D) Migrated cells (purple area) were quantified based on optical density (OD) values. ${ }^{*} P<0.05$, Huh $7^{\mathrm{CD}_{133+}}(48 \mathrm{~h}) v s . \mathrm{Huh} 7^{\mathrm{CD} 133^{-}}$cells $(48 \mathrm{~h}) .{ }^{*} P<0.05$, shADAM1 $7^{\mathrm{CD} 133+}(48 \mathrm{~h}) v s$. Huh $7^{\mathrm{CD} 133+}$ cells $(48 \mathrm{~h})$. (E) Invasion assay of shADAM1 $7^{\mathrm{CD} 133+}$ and shNC $\mathrm{CD}^{\mathrm{CD} 13+}$ cells was using Matrigel-coated Transwells. ${ }^{*} P<0.05$, shADAM17 ${ }^{\mathrm{CD} 133+}(48 \mathrm{~h}) v s . \operatorname{shNC}^{\mathrm{CD} 133+}(48 \mathrm{~h})$. 
Furthermore, to determine whether NICD translocates into the nucleus and activates transcription of genes, HES1 protein levels were determined using Western blotting. As shown in Figures 8C and 8D, HES1 expression was reduced significantly at 24 and $48 \mathrm{~h}$ after irradiation in shADAM $17^{\mathrm{CD} 133+}$ cells compared with shNC ${ }^{\mathrm{CD} 133+}$ cells. Taken together, our results suggest that the Notch pathway is inhibited by suppression of ADAM17 during metastasis of CD133-expressing liver CSCs after radiotherapy.

\section{DISCUSSION}

In the present study, we showed that stem-like cells play an important role in the radioresistance and metastatic potential of HCC. More specifically, the CD133expressing Huh7 cell subpopulation showed greater resistance to sublethal irradiation and enhanced invasion and migration, which reflect metastatic potential. In the present study, our results demonstrated that irradiated CD133 (+) LCSCs have more predominantly metastatic potential than CD133 (-) LCSCs in the metastasis in vivo mice model which was established by tail vein injection of tumor cells. These results are consistent with a previous report that CD133-expressing cancer stem cells within gliomas are less sensitive to radiation-induced apoptosis and the fraction of CD133-expressing cells is increased in in vitro cultures after irradiation [12]. We recently revealed that CD133-expressing liver cancer cells have anti-apoptotic and radioresistance properties which are mediated by activation of the MAPK/PI3K signaling pathway [14]. Given the high tumorigenic capacity of HCC stem cells, disrupting the radioresistance of liver CSCs may enhance the efficacy of radiotherapy for HCC. MMP activation in tumor metastasis allows tumor cells to access blood vessels, migrate to and invade target organs, ultimately leading to metastasis [40]. Among them,
A

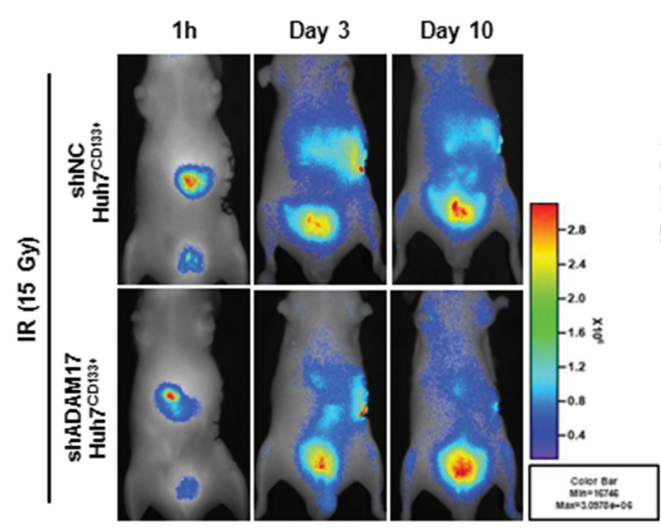

B

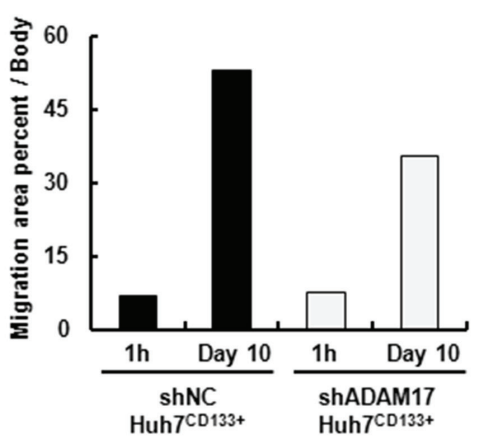

C

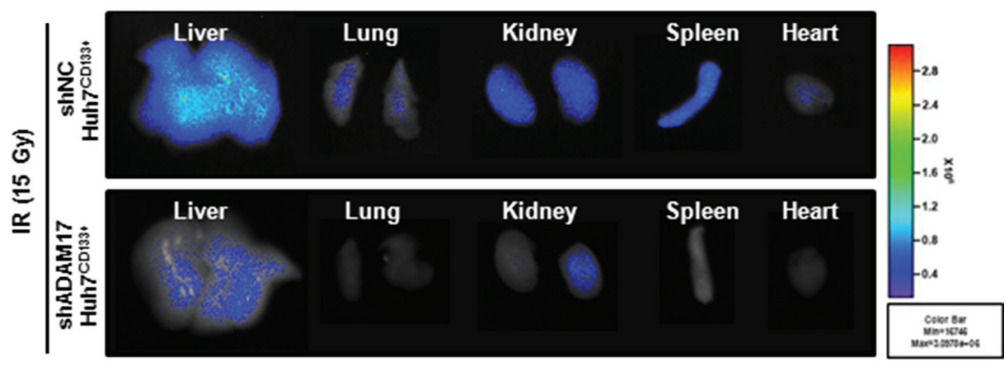

D

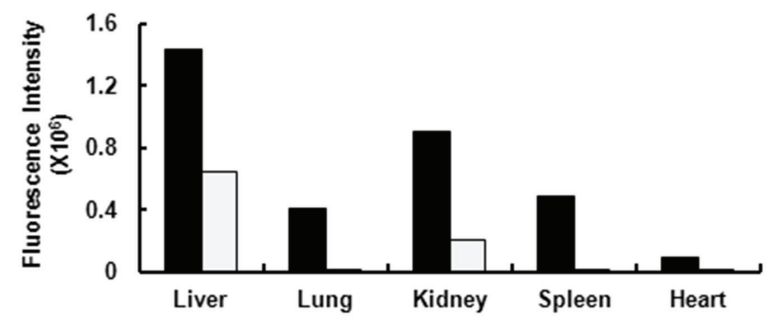

E

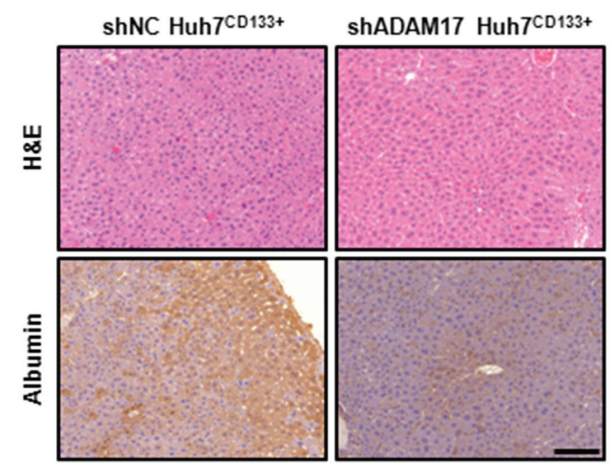

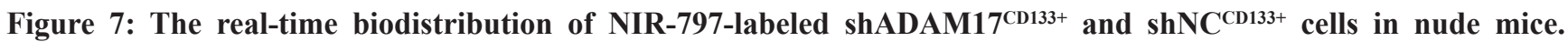
(A) Fluorescent images of NIR-797-stained shNC ${ }^{\mathrm{CD} 133+}$ (up) and shADAM17 ${ }^{\mathrm{CD} 133+}$ cell migration (down) $1 \mathrm{~h}$ and 3 and 10 days after intrasplenic vein injection in nude mice after 15- Gy irradiation $\left(2 \times 10^{5}\right.$ cells/mouse). (B) Migration area percentages were analyzed using the Maestro Imaging System and Optimas 6.5 software. (C) Fluorescent images show the migration to other organs of NIR-797-stained shADAM17 $7^{\mathrm{CD} 133^{+}}$and $\mathrm{shNC} \mathrm{CD}^{\mathrm{C} 133^{+}}$cells after $15-$ Gy irradiation following intrasplenic vein injection. (D) NIR signal intensity of mouse organs was obtained using the Maestro Imaging System. (E) Mice liver sections stained with H \& E (TOP). Representative human albumin immunohistochemistry staining of cell migration in mice liver (Bottom). Scale bar, $100 \mu \mathrm{m}$. 
MMP-2 and MMP-9 play key roles in tumor invasion and metastasis because of their specificity for type IV collagen, which is the principal component of the basement membrane [41]. In our study, we demonstrated that radiation-induced MMP-2 and MMP-9 activities were more predominantly increased in Huh $7^{\mathrm{CD} 133+}$ cell culture supernatant after irradiation. In addition, the secretion of VEGF, which plays an essential role in carcinogenesis and metastasis, was significantly increased. These results are consistent with a previous report that CD133-expressing glioma stem cells can promote tumor angiogenesis through hypoxia-induced elevated VEGF secretion [42, 43]. Taken together, our results showed that irradiation of an HCC cell line enriched in the CD133-expressing cell subpopulation led to metastatic potential, suggesting that radiotherapy rather than being curative may enhance tumor metastasis in HCC. Thus, the molecular mechanisms that regulate cell survival or death responses to ionizing radiation must be identified to develop novel therapies for HCC by targeting key signaling factors.

To investigate the mechanisms underlying the maintenance or reinforcement of the migration and invasion abilities of liver CSCs following irradiation,

A

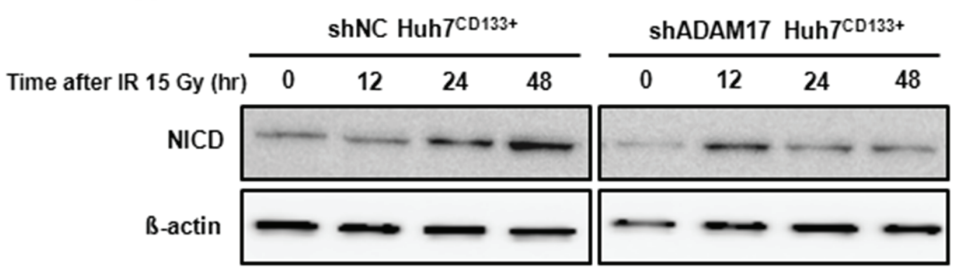

C

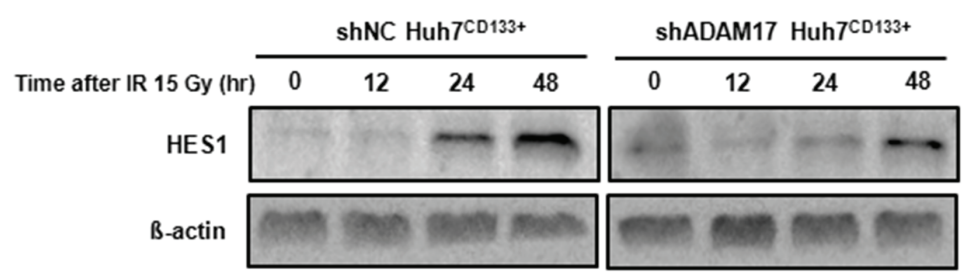

we performed comparative expression profiling of the $\mathrm{Huh} 7^{\mathrm{CD} 133^{+}}$and Huh $7^{\mathrm{CD} 133^{-}}$cell subpopulations. We identified 14 metastasis-associated genes responsible for cell invasion, migration or angiogenesis in enriched Huh $7^{\mathrm{CD} 133+}$ cells after irradiation. Among them, ADAM17, which is involved in tumorigenesis, was significantly increased at both the mRNA and protein levels in enriched Huh $7^{\mathrm{CD} 133+}$ cells following irradiation. A recent study showed that ADAM17 is decreased by hypoxia and contributes to hypoxia-induced cisplatin resistance via the EGFR/PI3K/Akt pathway in HCC [23]. In this study, we demonstrated for the first time that ADAM17 expression contributes to the invasion and migration of enriched Huh $7^{\mathrm{CD} 133+}$ cells after irradiation. To further investigate the biological role of ADAM17 in the radiation-associated metastatic potential of CSC-enriched HCC cells, we suppressed ADAM17 expression using stable shRNA in enriched Huh $7^{\mathrm{CD} 133+}$ cells after irradiation. Silencing of ADAM17 significantly inhibited the migration and invasiveness of enriched Huh $7^{\mathrm{CD} 133+}$ cells after irradiation. Our results are consistent with a previous report that ADAM17 is associated with microvascular invasion in

\section{B}

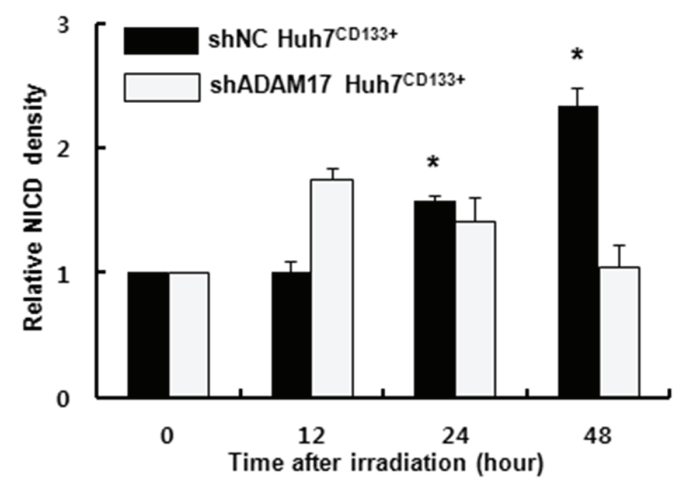

D

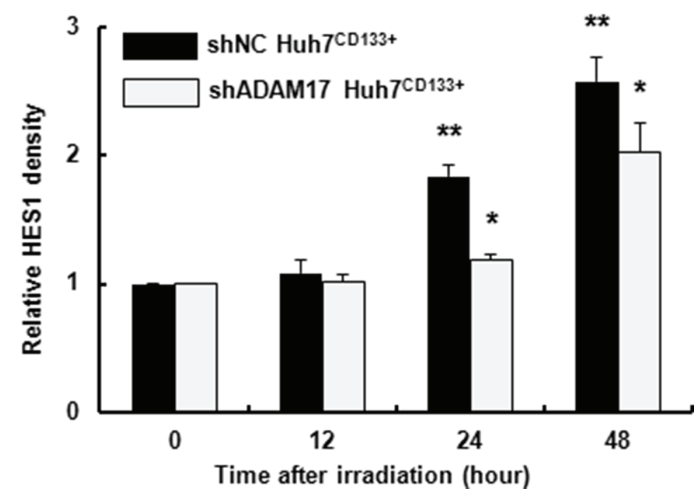

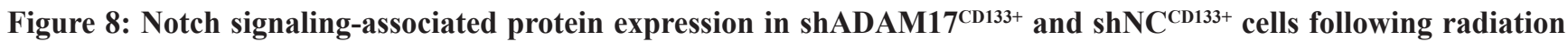
exposure. (A) Western blot analysis of NICD protein levels in shADAM1 $7^{\mathrm{CD} 133+}$ and $\mathrm{ShNC}^{\mathrm{CD} 133+}$ cells after 15 - Gy irradiation. $\beta$-actin was used as a loading control. (B) The band densities were quantified using the TINA imaging analysis software and normalized to $\beta$-actin expression. The data shown are the means $\pm \mathrm{SE}$ of three independent experiments. ${ }^{*} P<0.05$, shNC ${ }^{\mathrm{CD} 133+} v s$. controls. (C) Western blot analysis of HES1 protein levels in shADAM1 $7^{\mathrm{CD} 133+}$ and $\mathrm{shNC} \mathrm{CD}^{\mathrm{C} 133+}$ cells after 15 - Gy irradiation. $\beta$-actin was used as a loading control. (D) The band densities were quantified using the TINA imaging analysis software and normalized to $\beta$-actin expression. The data shown are the means $\pm \mathrm{SE}$ of three independent experiments. ${ }^{*} P<0.05$, shADAM1 ${ }^{\mathrm{CD} 133^{+}} v s$. controls. ${ }^{*} P<0.01$, shNC ${ }^{\mathrm{CD} 133^{+}} v s$. controls. 
HCC, which results in disease progression [44]. Next, we determined whether these in vitro findings could be replicated in vivo. ADAM17-suppressed Huh7 $7^{\mathrm{CD} 133+}$ cell migration was significantly inhibited compared with that of ADAM17-nonsuppressed Huh7 $7^{\mathrm{CD} 133^{+}}$cells after irradiation based on the NIR fluorescence signals detected by in vivo real-time imaging analysis. These results suggest that ADAM17 is involved in the radiationassociated metastatic potential of CSC-enriched HCC cells after irradiation and thus may be a potential HCC therapeutic target. Moreover, a recent study reported that a specific anti-ADAM17 antibody showed anti-tumor effects in an ovarian cancer model in vivo [45]. In this regard, specific ADAM17 inhibition in combination with radiotherapy provides a promising therapeutic approach for patients with unrespectable HCC.

The Notch signaling pathway is involved in tumorigenesis and metastasis in various human tumors and plays an important role in CSCs [46]. Inhibition of Notch induces apoptosis and differentiation in CD133expressing stem-like cells enriched from medulloblastoma cell lines [47]. Moreover, a recent report demonstrated that inhibition of the Notch signaling pathway inhibits HCC cell invasion by inactivating MMP-2, MMP-9 and VEGF [25]. A more recent study demonstrated that Notch inhibition in irradiated glioma stem cells dramatically increased cell death within 3 days after radiation, indicating a key role in post-radiation survival of glioma stem cells [48]. Another study examining the relationship between ADAM17 and Notch signaling showed that ADAM17 is a key enzyme for activation of the Notch signaling pathway, and that inhibition of its activity effectively promotes apoptosis and impairs invasion ability in renal cell carcinoma [49]. Based on the above results, we investigated the correlation between ADAM17 and Notch signaling in enriched CD133-expressing liver CSCs after radiation. In our study, Notch signaling was significantly reduced in irradiated CD133-expressing liver CSCs following stable knockdown of the ADAM17 gene. Additionally, HES1 expression was significantly reduced in shADAM1 $7^{\mathrm{CD} 133+}$ cells after irradiation compared with shNC ${ }^{\mathrm{CD} 133+}$ cells. Collectively, our results suggest that inhibition of ADAM17 suppresses the Notch signaling pathway, resulting in decreased MMP-2, MMP-9 and VEGF, leading to inhibition of invasion or migration by CD133-expressing liver CSCs after irradiation. CD133-expressing CSCs were shown to be responsible for cell invasion and migration after radiation and their radiation-induced metastatic potential could be prevented by suppression of ADAM17 signaling, suggesting ADAM17 to be a potential target for radiotherapy in patients with HCC. In conclusion, our findings indicate that after irradiation of HCC cells CD133-expressing liver CSCs have significant metastatic capabilities, the maintenance of which might be inhibited by suppression of ADAM17. Therefore, suppression of ADAM17 may reduce the metastatic potential of liver CSCs via downregulation of ADAM17.

\section{MATERIALS AND METHODS}

\section{Cell culture and irradiation}

Human hepatoma cells (Huh7, Hep3B, SK-hep1 and PLC/PRF-5) were grown in Dulbecco's modified Eagle's medium (DMEM; Invitrogen, Carlsbad, CA, USA) supplemented with $10 \%$ fetal bovine serum (FBS, Invitrogen), $100 \mu \mathrm{g} / \mathrm{mL}$ penicillin and $0.25 \mu \mathrm{g} / \mathrm{mL}$ streptomycin (Invitrogen) and maintained in a humidified incubator at $37^{\circ} \mathrm{C}$ with $5 \% \mathrm{CO}_{2}$. Cells were preincubated with serum-free DMEM and irradiated at 15- Gy using a cesium-137 source delivering 3.1 Gy/min (Gammacell 3000 Elan irradiator; Best Theratronics, Ottawa, Canada). After 15-Gy irradiation, the cells were plated at the same density for the in vitro study.

\section{RNA interference}

A small interfering RNA (siRNA) method was used to knockdown ADAM17. The ADAM17 siRNA sense sequences were 5-CAUCAAGUACUGAACGUUUdTdT-3 and 5-AAACGUUCAGUACUUGAUGdTdT-3. Control cells were subjected to mock transfection with scrambled siRNA. Transfection was performed using G-fectin (Genolution, Korea) following the manufacturer's protocol.

\section{Flow cytometric analysis}

Cells were incubated at $4{ }^{\circ} \mathrm{C}$ with a phycoerythrinconjugated anti-CD133/1 antibody (Miltenyi Biotec, Auburn, CA, USA) and analyzed by flow cytometry (FACSCalibur; BD Biosciences, San Jose, CA, USA). Huh $7^{\mathrm{CD} 133^{+}}$and Huh $7^{\mathrm{CD} 133^{-}}$cells were sorted using a FACSCalibur cell sorter. Isotype-matched mouse IgG was used as a control.

\section{DNA microarray-based gene expression profiling in CD133-expressing liver CSCs following radiation exposure}

DNA microarray-based gene expression profiling in CD133-expressing liver cancer cells following radiation exposure was performed. The mRNA levels of Huh $7^{\text {CD133+ }}$ and Huh $7^{\mathrm{CD} 133-}$ cells at 12 and $24 \mathrm{~h}$ post-irradiation and controls before irradiation were analyzed using the Illumina microarray platform (Sentrix Human HT-12v1 BeadChip; Illumina, San Diego, CA, USA). Total RNAs were extracted, reverse-transcribed, and amplified according to the manufacturer's instructions. The integrity of total RNA was analyzed using the 2100 Bioanalyzer (Agilent Technologies, Santa Clara, CA, USA). In vitro transcription was performed to generate cRNA, which was hybridized onto each array. The arrays were scanned using a Bead Station (Illumina). Under each condition, we performed gene expression profiling of two biological replicates obtained from independent cell cultures. The probe 
intensities were normalized using quantile normalization in beadarray 1. The probes were annotated using lumi 1.4, an R/Bioconductor package. The full dataset was submitted to Gene Expression Omnibus under submission number (GSE22247). Differentially expressed genes (DEGs) identified by cDNA microarray comparisons were assigned to associate the union of DEGs with GO Biological Processes (GOBPs) using the Database for Annotation, Visualization, and Integrated Discovery (DAVID). Several GOBPs and KEGG pathways in which the DEGs were significantly enriched $(p \leq 0.05)$ were identified, including metastasis-associated processes (motility/cytoskeleton, invasion, adhesion and angiogenesis).

\section{ADAM17 knockdown with stable short-hairpin SiRNA (shRNA)}

To establish a stable Huh7 cell line depleted of ADAM17 expression, cells were infected using a shorthairpin RNA (shRNA)-lentiviral infection system (Sigma-Aldrich Co.). We constructed an ADAM17 shRNA- carrying lentiviral vector, LV-ADAM17. The shRNA negative control-lentiviral particle (LV-NC) was used as a negative control. To generate stable cells, $1 \times 10^{5}$ Huh7 cells were plated on 12-well plates, transduced with $5 \mathrm{MOI}$ lentiviral particles (using $8 \mu \mathrm{g} / \mathrm{mL}$ hexadimethrine bromide [(Sigma-Aldrich Co.]), and incubated in DMEM containing puromycin $(5 \mu \mathrm{g} / \mathrm{mL})$ at $37^{\circ} \mathrm{C}$ with $5 \% \mathrm{CO}_{2}$. Suppression of ADAM17 in stable cells was confirmed by RT-PCR and Western blot analyses.

\section{Western blotting}

Protein extracts were resolved on $12 \%$ and 10\% SDS-PAGE gels, transferred onto nitrocellulose membranes (Schleicher \& Schuell, Dassel, Germany) and blocked in 5\% skim milk. The following primary antibodies were used according to the manufacturer's instructions: anti-CD133 (Santa Cruz Biotechnology, Santa Cruz, CA, USA), ADAM17 (ab cam), NICD (Cell Signaling Technology, Beverly, MA, USA), MTSS1 (Santa Cruz Biotechnology), HES1 (Santa Cruz Biotechnology) and $\beta$-actin (Sigma-Aldrich Co.). After incubation with horseradish peroxidase (HRP)-conjugated anti-mouse or anti-rabbit secondary antibodies (Amersham Biosciences, Cardiff, UK), specific protein bands were visualized using enhanced chemiluminescence (Amersham Biosciences). The density of each band was measured using the TINA software.

\section{Migration assay}

Huh $7^{\mathrm{CD} 133^{+}}$and Huh7 $7^{\mathrm{CD} 133^{-}}$cells were grown to $70 \%$ confluence in two $60-\mathrm{mm}$ plates prior to experimentation for $12 \mathrm{~h}$ in $10 \% \mathrm{FBS}$ after radiation treatment. Additionally, cells were washed and detached using $2 \mathrm{mM}$ ethylenediaminetetraacetic acid (EDTA) in PBS. After complete detachment, cells were resuspended in serum-free medium. Migration of $\mathrm{Huh} 7^{\mathrm{CD} 133^{+}}$and Huh7 ${ }^{\mathrm{CD} 133^{-}}$cells was determined using a 24-well Transwell chamber system (Costar 3422, Corning Inc., NY, USA). Huh $7^{\mathrm{CD} 133+}$ and Huh $7^{\mathrm{CD} 133+}$ cells were seeded in the upper chamber at $3 \times 10^{4} / \mathrm{mL}$ in $0.2 \mathrm{~mL}$ serum-free DMEM medium. Medium supplemented with $10 \%$ fetal bovine serum was placed in the bottom well in a volume of 0.8 $\mathrm{ml}$. After incubation for 12, 24 and $48 \mathrm{~h}$, non-migrating cells on the upper side of the filter were removed with a cotton swab. The filters were stained with the Three-Step Stain Set (Diff-Quik; Sysmex, Kobe, Japan), and the cells that migrated to the lower side of the filter were counted under a slide scanner (Pannoramic MIDI; 3DHISTECH Ltd., Budapest, Hungary) in five randomly selected fields $(\times 200)$.

\section{Wound healing assay}

Cell motility was assessed using a wound-healing assay and liver cell imaging. Huh $7^{\mathrm{CD} 133^{+}}$and Huh $7^{\mathrm{CD} 133^{-}}$ cells were grown to a confluent monolayer on Nunclon 24-well plates (NUNC, MA, USA), serum-starved for $24 \mathrm{~h}$ and induced with dexamethasone for another $24 \mathrm{~h}$. Then, monolayers were wounded using a disposable pipette tip. Wound closure was monitored for $48 \mathrm{~h}$ using the Cell-IQ real-time image capture system (Chip-Man Technologies Ltd, Tampere, Finland). To determine whether wound closure was the result of cell migration, cells were counted followed by Optimas 6.5 software system.

\section{Gelatin zymography}

Huh $7^{\mathrm{CD} 133^{+}}$and Huh7 $7^{\mathrm{CD} 133-}$ cell culture media were mixed with non-denatured sample buffer (1 M Tris- $\mathrm{Cl} \mathrm{pH}$ $6.8,1 \%$ bromophenol blue, $20 \%$ SDS). The mixture was electrophoresed on a $10 \%$ polyacrylamide gel containing $1 \mathrm{mg} / \mathrm{mL}$ gelatin (Sigma-Aldrich Co., St Louis, MO, USA) and the gel was rinsed twice in distilled water with $2.5 \%$ Triton X-100 for $10 \mathrm{~min}$ and then incubated in activation buffer $\left(50 \mathrm{mM}\right.$ Tris buffer, $\mathrm{pH} 7.4$ containing $5 \mathrm{mM} \mathrm{CaCl}_{2}$ and $1 \mu \mathrm{M} \mathrm{ZnCl}_{2}$ ) at $4^{\circ} \mathrm{C}$ for $12 \mathrm{~h}$. In gels stained with Coomassie brilliant blue R-250, MMP-2 appeared as a clear area and the band density was measured using the Multigage imaging software.

\section{Reverse transcription polymerase chain reaction (PCR)}

Total RNA was prepared from shRNA LV-NC and ADMA17 shRNA lentiviral particles cells using TRIzol reagent (Invitrogen) according to the manufacturer's instructions. cDNA was synthesized from $2-\mu \mathrm{g}$ total RNA and a random primer and Taq polymerase (Promega) were used for RT-PCR. The target primer sequences used were 
as follows: ADAM17 forward: 5'-TTT CAA GGT CGT GGT GGT GG-3', ADAM17 reverse: 5'-TTC CCC TCT GCC CAT GTA TC-3', and $\beta$-actin forward: 5'- GGC ACC ACA CCT TCT ACA ATG A-3', $\beta$-actin reverse: $5^{\prime}$ - CCC TCG TAG ATG GGC ACA GT -3'.

\section{Enzyme-linked immunosorbent assay (ELISA)}

The expression levels of VEGF, were quantified in culture media using ELISA. In brief, culture medium was dispensed into 96-well microtiter plates (Nalgen Nunc) with coating buffer and incubated at $4^{\circ} \mathrm{C}$ overnight. The plates were then rinsed with PBS with $0.05 \%$ Tween-20 (PBST), reacted first with specific antibodies against VEGF at $37^{\circ} \mathrm{C}$ for $1 \mathrm{~h}$ and second with the supplied horseradish peroxidase (HRP)-conjugated goat antimouse IgG (Zymed, San Francisco, CA, USA; diluted 1:3,000). After washing three times with PBST, the plates were developed by incubation for $30 \mathrm{~min}$ at room temperature with 3,3', 5,5-tetramethyl benzidine (TMB) as the substrate. The reaction was stopped by addition of $1 \mathrm{M} \mathrm{H}_{2} \mathrm{SO}_{4}$ and the absorbance at $450 \mathrm{~nm}$ was determined using a microplate reader.

\section{Histologic analysis}

Formalin-fixed and paraffin-embedded liver specimens were sectioned and stained with hematoxylin and eosin (H \& E). In addition, immunohistochemistry for human albumin was performed using standard protocols. After blocking endogenous peroxide activity with $1 \mathrm{wt} \%$ goat serum in PBS, the sections were incubated with primary antibody against human-albumin diluted 1:500 in antibody diluent at $4{ }^{\circ} \mathrm{C}$ overnight. After washing, the peroxidase EnVision System (HPR rabbit/Mouse Envision System TM, DakoCytomation, Denmark) was applied at room temperature for 5-10 min. Peroxidase activity was detected using 3,3-diaminobenzidine tetrachloride and hematoxylin counterstaining.

\section{Animal and tumor cell inoculation}

All animal experiments were performed in accordance with institutional guidelines and were approved by the Institutional Animal Care and Use Committee of The Catholic University of Korea. Four week-old Balb/c nude male mice (Central Lab. Animal Inc., Seoul, Korea) were housed in the animal facility for least 2 weeks before starting the experiments. To investigate the metastatic potential of irradiated LCSCs, a total of $10^{6}$ irradiated Huh $7^{\mathrm{CD} 133+}$ or Huh $7^{\mathrm{CD} 133-}$ cells per mouse were injected via the tail vein. Mice were assessed daily for tumor formation by palpation and survival was monitored daily. The mice were euthanized after anesthesia at 10 weeks to determine the extent of metastasis. The organs were separated and fixed in formaldehyde for H \& E staining.

\section{In vivo imaging study}

To assess the migration ability of liver CSCs in vivo, we performed a cell tracking in vivo real-time imaging study using near-infrared fluorescent magnetic NEO-LIVE ${ }^{\mathrm{TM}}$-Magnoxide 797 nanoparticles (NIR797; Biterials, Seoul, Korea) at $0.4 \mathrm{mg} / \mathrm{mL}$. All procedures were performed according to the manufacturer's instructions. After irradiation, $2 \times 10^{5}$ cells were marked with NIR-797 for near-infrared fluorescence imaging and then injected into the spleen of the nude mice, and fluorescence images were obtained using the Maestro Imaging System (Cambridge Research \& Instrumentation Inc., MA, USA) for data acquisition and analysis.

\section{Statistical analysis}

All data are expressed as the means \pm standard error of the mean from at least three independent experiments. Significant differences between among test conditions were identified using the Student's $t$-test. $* P<0.05$, $* * P<0.01$ and $* * * P<0.001$ was considered significant.

\section{ACKNOWLEDGMENTS AND FUNDING}

This work was partially supported by grants of the National Research Foundation of Korea grant funded by the Korea government (NRF-2010-0025007) and the BioSynergy Research Project (NRF-2013M3A9C4078136) of the Ministry of Science, ICT and Future Planning through the National Research Foundation.

\section{CONFLICTS OF INTEREST}

All authors declared that they had no conflicts of interests.

\section{REFERENCES}

1. Parkin DM, Bray F, Ferlay J, Pisani P. Global cancer statistics, 2002. CA. 2005; 55:74-108.

2. El-Serag HB, Lau M, Eschbach K, Davila J, Goodwin J. Epidemiology of hepatocellular carcinoma in Hispanics in the United States. Archives of internal medicine. 2007; 167:1983-1989.

3. Bruix J, Sherman M, American Association for the Study of Liver D. Management of hepatocellular carcinoma: an update. Hepatology. 2011; 53:1020-1022.

4. Price TR, Perkins SM, Sandrasegaran K, Henderson MA, Maluccio MA, Zook JE, Tector AJ, Vianna RM, ohnstone PA, Cardenes HR. Evaluation of response after stereotactic body radiotherapy for hepatocellular carcinoma. Cancer. 2012; 118:3191-3198. 
5. Kaliski A, Maggiorella L, Cengel KA, Mathe D, Rouffiac V, Opolon P, Lassau N, Bourhis J, Deutsch E. Angiogenesis and tumor growth inhibition by a matrix metalloproteinase inhibitor targeting radiation-induced invasion. Molecular cancer therapeutics. 2005; 4:1717-1728.

6. Lai PP, Perez CA, Lockett MA. Prognostic significance of pelvic recurrence and distant metastasis in prostate carcinoma following definitive radiotherapy. International journal of radiation oncology, biology, physics. 1992; 24:423-430.

7. Huang EY, Wang CJ, Chen HC, Fang FM, Huang YJ, Wang CY, Hsu HC. Multivariate analysis of para-aortic lymph node recurrence after definitive radiotherapy for stage IB-IVA squamous cell carcinoma of uterine cervix. International journal of radiation oncology, biology, physics. 2008; 72:834-842.

8. Knizetova P, Darling JL, Bartek J. Vascular endothelial growth factor in astroglioma stem cell biology and response to therapy. Journal of cellular and molecular medicine. 2008; 12:111-125.

9. Iwasaki H, Suda T. Cancer stem cells and their niche. Cancer science. 2009; 100:1166-1172.

10. Grosse-Gehling P, Fargeas CA, Dittfeld C, Garbe Y, Alison MR, Corbeil D, Kunz-Schughart LA. CD133 as a biomarker for putative cancer stem cells in solid tumours: limitations, problems and challenges. The Journal of pathology. 2013; 229:355-378.

11. Yamashita T, Wang XW. Cancer stem cells in the development of liver cancer. The Journal of clinical investigation. 2013; 123:1911-1918.

12. Bao S, Wu Q, McLendon RE, Hao Y, Shi Q, Hjelmeland AB, Dewhirst MW, Bigner DD, Rich JN. Glioma stem cells promote radioresistance by preferential activation of the DNA damage response. Nature. 2006; 444:756-760.

13. Diehn M, Cho RW, Lobo NA, Kalisky T, Dorie MJ, Kulp AN, Qian D, Lam JS, Ailles LE, Wong M, Joshua B, Kaplan MJ, Wapnir I, et al. Association of reactive oxygen species levels and radioresistance in cancer stem cells. Nature. 2009; 458:780-783.

14. Piao LS, Hur W, Kim TK, Hong SW, Kim SW, Choi JE, Sung PS, Song MJ, Lee BC, Hwang D, Yoon SK. CD133+ liver cancer stem cells modulate radioresistance in human hepatocellular carcinoma. Cancer letters. 2012; 315:129-137.

15. Cheng JC, Chou CH, Kuo ML, Hsieh CY. Radiationenhanced hepatocellular carcinoma cell invasion with MMP-9 expression through PI3K/Akt/NF-kappaB signal transduction pathway. Oncogene. 2006; 25:7009-7018.

16. Li T, Zeng ZC, Wang L, Qiu SJ, Zhou JW, Zhi XT, Yu HH, Tang ZY. Radiation enhances long-term metastasis potential of residual hepatocellular carcinoma in nude mice through TMPRSS4-induced epithelial-mesenchymal transition. Cancer gene therapy. 2011; 18:617-626.

17. Zatovicova M, Sedlakova O, Svastova E, Ohradanova A, Ciampor F, Arribas J, Pastorek J, Pastorekova S.
Ectodomain shedding of the hypoxia-induced carbonic anhydrase IX is a metalloprotease-dependent process regulated by TACE/ADAM17. British journal of cancer. 2005; 93:1267-1276.

18. Mullberg J, Durie FH, Otten-Evans C, Alderson MR, Rose-John S, Cosman D, Black RA, Mohler KM. A metalloprotease inhibitor blocks shedding of the IL-6 receptor and the p60 TNF receptor. Journal of immunology. 1995; 155:5198-5205.

19. Borrell-Pages M, Rojo F, Albanell J, Baselga J, Arribas J. TACE is required for the activation of the EGFR by TGFalpha in tumors. The EMBO journal. 2003; 22:1114-1124.

20. Kenny PA. Tackling EGFR signaling with TACE antagonists: a rational target for metalloprotease inhibitors in cancer. Expert opinion on therapeutic targets. 2007; 11:1287-1298.

21. McGowan PM, Ryan BM, Hill AD, McDermott E, O’Higgins N, Duffy MJ. ADAM-17 expression in breast cancer correlates with variables of tumor progression. Clinical cancer research. 2007; 13:2335-2343.

22. Zheng X, Jiang F, Katakowski M, Kalkanis SN, Hong X, Zhang X, Zhang ZG, Yang H, Chopp M. Inhibition of ADAM17 reduces hypoxia-induced brain tumor cell invasiveness. Cancer science. 2007; 98:674-684.

23. Wang XJ, Feng CW, Li M. ADAM17 mediates hypoxiainduced drug resistance in hepatocellular carcinoma cells through activation of EGFR/PI3K/Akt pathway. Molecular and cellular biochemistry. 2013; 380:57-66.

24. Stylianou S, Clarke RB, Brennan K. Aberrant activation of notch signaling in human breast cancer. Cancer research. 2006; 66:1517-1525.

25. Zhou L, Wang DS, Li QJ, Sun W, Zhang Y, Dou KF. Downregulation of the Notch signaling pathway inhibits hepatocellular carcinoma cell invasion by inactivation of matrix metalloproteinase- 2 and -9 and vascular endothelial growth factor. Oncology reports. 2012; 28:874-882.

26. Hermann PC, Huber SL, Herrler T, Aicher A, Ellwart JW, Guba M, Bruns CJ, Heeschen C. Distinct populations of cancer stem cells determine tumor growth and metastatic activity in human pancreatic cancer. Cell stem cell. 2007; $1: 313-323$.

27. Kucia M, Reca R, Miekus K, Wanzeck J, Wojakowski W, Janowska-Wieczorek A, Ratajczak J, Ratajczak MZ. Trafficking of normal stem cells and metastasis of cancer stem cells involve similar mechanisms: pivotal role of the SDF-1-CXCR4 axis. Stem cells. 2005; 23:879-894.

28. Paley PJ, Staskus KA, Gebhard K, Mohanraj D, Twiggs LB, Carson LF, Ramakrishnan S. Vascular endothelial growth factor expression in early stage ovarian carcinoma. Cancer. 1997; 80:98-106.

29. Yamaguchi R, Yano H, Iemura A, Ogasawara S, Haramaki M, Kojiro M. Expression of vascular endothelial growth factor in human hepatocellular carcinoma. Hepatology. 1998; 28:68-77. 
30. Park JS, Qiao L, Su ZZ, Hinman D, Willoughby K, McKinstry R, Yacoub A, Duigou GJ, Young CS, Grant S, Hagan MP, Ellis E, Fisher PB, et al. Ionizing radiation modulates vascular endothelial growth factor (VEGF) expression through multiple mitogen activated protein kinase dependent pathways. Oncogene. 2001; 20:3266-3280.

31. Gao Y, Ruan B, Liu W, Wang J, Yang X, Zhang Z, Li X, Duan J, Zhang F, Ding R, Tao K, Dou K. Knockdown of CD44 inhibits the invasion and metastasis of hepatocellular carcinoma both in vitro and in vivo by reversing epithelialmesenchymal transition. Oncotarget. 2015; 6:7828-7837. doi: 10.18632/oncotarget.3488.

32. Xiao LJ, Lin P, Lin F, Liu X, Qin W, Zou HF, Guo L, Liu W, Wang SJ, Yu XG. ADAM17 targets MMP-2 and MMP-9 via EGFR-MEK-ERK pathway activation to promote prostate cancer cell invasion. International journal of oncology. 2012; 40:1714-1724.

33. Lin J, Liu J, Wang Y, Zhu J, Zhou K, Smith N, Zhan X. Differential regulation of cortactin and N-WASP-mediated actin polymerization by missing in metastasis (MIM) protein. Oncogene. 2005; 24:2059-2066.

34. Katakowski M, Jiang F, Zheng X, Gutierrez JA, Szalad A, Chopp M. Tumorigenicity of cortical astrocyte cell line induced by the protease ADAM17. Cancer science. 2009; 100:1597-1604.

35. Xing F, Kobayashi A, Okuda H, Watabe M, Pai SK, Pandey PR, Hirota S, Wilber A, Mo YY, Moore BE, Liu W, Fukuda K, Iiizumi M, et al. Reactive astrocytes promote the metastatic growth of breast cancer stem-like cells by activating Notch signalling in brain. EMBO molecular medicine. 2013; 5:384-396.

36. Kavian N, Servettaz A, Mongaret C, Wang A, Nicco C, Chereau C, Grange P, Vuiblet V, Birembaut P, Diebold MD, Weill B, Dupin N, Batteux F. Targeting ADAM-17/notch signaling abrogates the development of systemic sclerosis in a murine model. Arthritis and rheumatism. 2010; 62:3477-3487.

37. Uyttendaele H, Closson V, Wu G, Roux F, Weinmaster G, Kitajewski J. Notch4 and Jagged-1 induce microvessel differentiation of rat brain endothelial cells. Microvascular research. 2000; 60:91-103.

38. Kingsley LA, Fournier PG, Chirgwin JM, Guise TA. Molecular biology of bone metastasis. Molecular cancer therapeutics. 2007; 6:2609-2617.
39. de la Pompa JL, Epstein JA. Coordinating tissue interactions: Notch signaling in cardiac development and disease. Developmental cell. 2012; 22:244-254.

40. Itoh Y, Nagase H. Matrix metalloproteinases in cancer. Essays in biochemistry. 2002; 38:21-36.

41. Zeng ZS, Cohen AM, Guillem JG. Loss of basement membrane type IV collagen is associated with increased expression of metalloproteinases 2 and 9 (MMP-2 and MMP-9) during human colorectal tumorigenesis. Carcinogenesis. 1999; 20:749-755.

42. Bao S, Wu Q, Sathornsumetee S, Hao Y, Li Z, Hjelmeland AB, Shi Q, McLendon RE, Bigner DD, Rich JN. Stem celllike glioma cells promote tumor angiogenesis through vascular endothelial growth factor. Cancer research. 2006; 66:7843-7848.

43. Hovinga KE, Stalpers LJ, van Bree C, Donker M, Verhoeff JJ, Rodermond HM, Bosch DA, van Furth WR. Radiationenhanced vascular endothelial growth factor (VEGF) secretion in glioblastoma multiforme cell lines - a clue to radioresistance? Journal of neuro-oncology. 2005; 74:99-103.

44. Ding $\mathrm{X}$, Yang LY, Huang GW, Wang W, Lu WQ. ADAM17 mRNA expression and pathological features of hepatocellular carcinoma. World journal of gastroenterology. 2004; 10:2735-2739.

45. Richards FM, Tape CJ, Jodrell DI, Murphy G. Anti-tumour effects of a specific anti-ADAM17 antibody in an ovarian cancer model in vivo. PloS one. 2012; 7:e40597.

46. Bolos V, Blanco M, Medina V, Aparicio G, Diaz-Prado S, Grande E. Notch signalling in cancer stem cells. Clinical \& translational oncology. 2009; 11:11-19.

47. Fan X, Matsui W, Khaki L, Stearns D, Chun J, Li YM, Eberhart CG. Notch pathway inhibition depletes stem-like cells and blocks engraftment in embryonal brain tumors. Cancer research. 2006; 66:7445-7452.

48. Wang J, Wakeman TP, Lathia JD, Hjelmeland AB, Wang XF, White RR, Rich JN, Sullenger BA. Notch promotes radioresistance of glioma stem cells. Stem cells. 2010; 28:17-28.

49. Guo Z, Jin X, Jia H. Inhibition of ADAM-17 more effectively down-regulates the Notch pathway than that of gamma-secretase in renal carcinoma. Journal of experimental \& clinical cancer research. 2013; 32:26. 